\title{
Stimuli-Responsive Templated Polymer as a Target Receptor for a Conformation-based Electrochemical Sensing
}

\section{Platform}

\author{
Habib M. N. Ahmad ${ }^{\dagger}$, Gaurab Dutta ${ }^{\dagger}$, John Csoros ${ }^{\star}, B_{0} \mathrm{Si}^{\ddagger}$, Rongfang Yang ${ }^{\ddagger}$, Jeffrey M. \\ Halpern ${ }^{\perp}$, W. Rudolf Seitz ${ }^{\ddagger}$, and Edward Song ${ }^{* \dagger, \S}$ \\ ${ }^{\dagger}$ Department of Electrical and Computer Engineering, ${ }^{\star}$ Department of Chemistry, ${ }^{\perp}$ Department \\ of Chemical Engineering, ${ }^{\S}$ Materials Science Program, University of New Hampshire, Durham, \\ NH 03824, United States
}

Corresponding Author*E-mail: Edward.Song@unh.edu. Phone: +1-603-862-5498.

\section{FTIR and NMR Analyses of the Synthesized Polymers}

The FTIR spectra from PNIPAM captured in Figure 2(b) and ( $\left.\mathbf{b}_{1}\right)$ show band vibrations from amide I and amide II, which correspond to the peaks at 1638 and $1536 \mathrm{~cm}^{-1}$, respectively. ${ }^{1}$ The amide $\mathrm{I}$ band has a significant contribution from $\mathrm{C}=\mathrm{O}$ stretching modes (from inter- and intramolecular hydrogen bonding of carbonyl groups) as well as a small contribution from C-N stretching. ${ }^{2}$ The amide II vibration arises primarily from a combination of $\mathrm{N}-\mathrm{H}$ in-plane bending and C-N stretching. The amide II peak for both the PNIPAM homopolymer and copolymer registered at $1638 \mathrm{~cm}^{-1}$, which indicates the integrity of the PNIPAM backbone in both samples. ${ }^{1,2}$ The change in the peak intensity of amide I and amide II between the copolymer and homopolymer samples are attributed to the smaller molar percentage of PNIPAM with more dehydrated $\mathrm{C}=\mathrm{O}$ groups (from both PNIPAM and MAA) and the hydrogen bonding between $\mathrm{C}=\mathrm{O}$ and $\mathrm{N}-\mathrm{H}$ of neighboring amide groups. ${ }^{3}$ The vibrations from the hydrophobic isopropyl groups in the PNIPAM

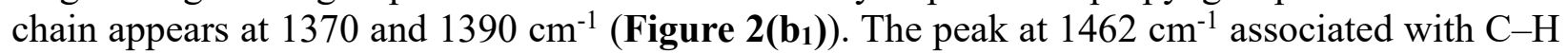
bending (scissoring) from $\mathrm{CH}_{3}$ groups arises from the backbone of PNIPAM. ${ }^{1,4}$ Figure 2(c) shows asymmetric $\mathrm{C}-\mathrm{N}-\mathrm{C}$ stretching at $1130 \mathrm{~cm}^{-1}$ associated with PNIPAM. ${ }^{1,5}$ The band vibrations around 2900-3000 $\mathrm{cm}^{-1}$ in Figure 2(d) due to C-H asymmetric bending arises from the combination of the side chain and the backbone of PNIPAM. ${ }^{1}$ A vibration at $3284 \mathrm{~cm}^{-1}$ is associated with N-H stretching from the PNIPAM. ${ }^{1,4}$ The wave around $3080 \mathrm{~cm}^{-1}$ is due to the $\mathrm{C}-\mathrm{H}$ vibration from the $\mathrm{CH}_{3}$ and $-\mathrm{CH}_{2}$ - groups present in both homopolymer and copolymer chains. ${ }^{3,6,7}$ The band vibration at $2880 \mathrm{~cm}^{-1}$ corresponding to the symmetric $\mathrm{C}-\mathrm{H}$ stretch is attributed to the terminal aldehydic group associated with PNIPAM. ${ }^{1}$

The presence of the RAFT chain transfer agent (DDMAT), MAA and VP in the copolymer were also verified with FTIR and NMR. A band at $1170 \mathrm{~cm}^{-1}$ shown in Figure $2(\mathbf{b} \&$ c) is 
attributed to the $\left(-\mathrm{C}\left(\mathrm{CH}_{3}\right)_{2}-\right)$ skeletal vibration of DDMAT. Weak asymmetric vibrations in the range $833-870 \mathrm{~cm}^{-1}$ are from the hydrophobic S-C-S stretching of the DDMAT. ${ }^{5,8}$ The O-H outof-plane vibration at $930 \mathrm{~cm}^{-1}$ from carboxylic acids arises possibly from the " $\mathrm{R}$ " group (Figure S8(d)) of DDMAT. ${ }^{5,9,10}$ Figure 2(b \& c) also shows that the copolymer exhibits two distinct weak band vibrations at $1711 \mathrm{~cm}^{-1}$ and $1031 \mathrm{~cm}^{-1}$, suggesting the inclusion of MAA and VP in the single polymer chain. ${ }^{11,12}$ The $1711 \mathrm{~cm}^{-1}$ band is associated with the carbonyl $\mathrm{C}=\mathrm{O}$ group stretch for saturated carboxylic acid ${ }^{12}$ and the $1031 \mathrm{~cm}^{-1}$ band is related to pyridine $\mathrm{C}-\mathrm{H}$ in- and out-of-plane bending. ${ }^{11}$ A relatively weak but distinct vibration at $1070 \mathrm{~cm}^{-1}$ for $\mathrm{C}-\mathrm{O}$ symmetric stretching also confirms the inclusion of MAA into the polymer chain. ${ }^{12}$

Nuclear Magnetic Resonance (NMR) Spectroscopy of Synthesized PNIPAM-MAA-VP Polymer:
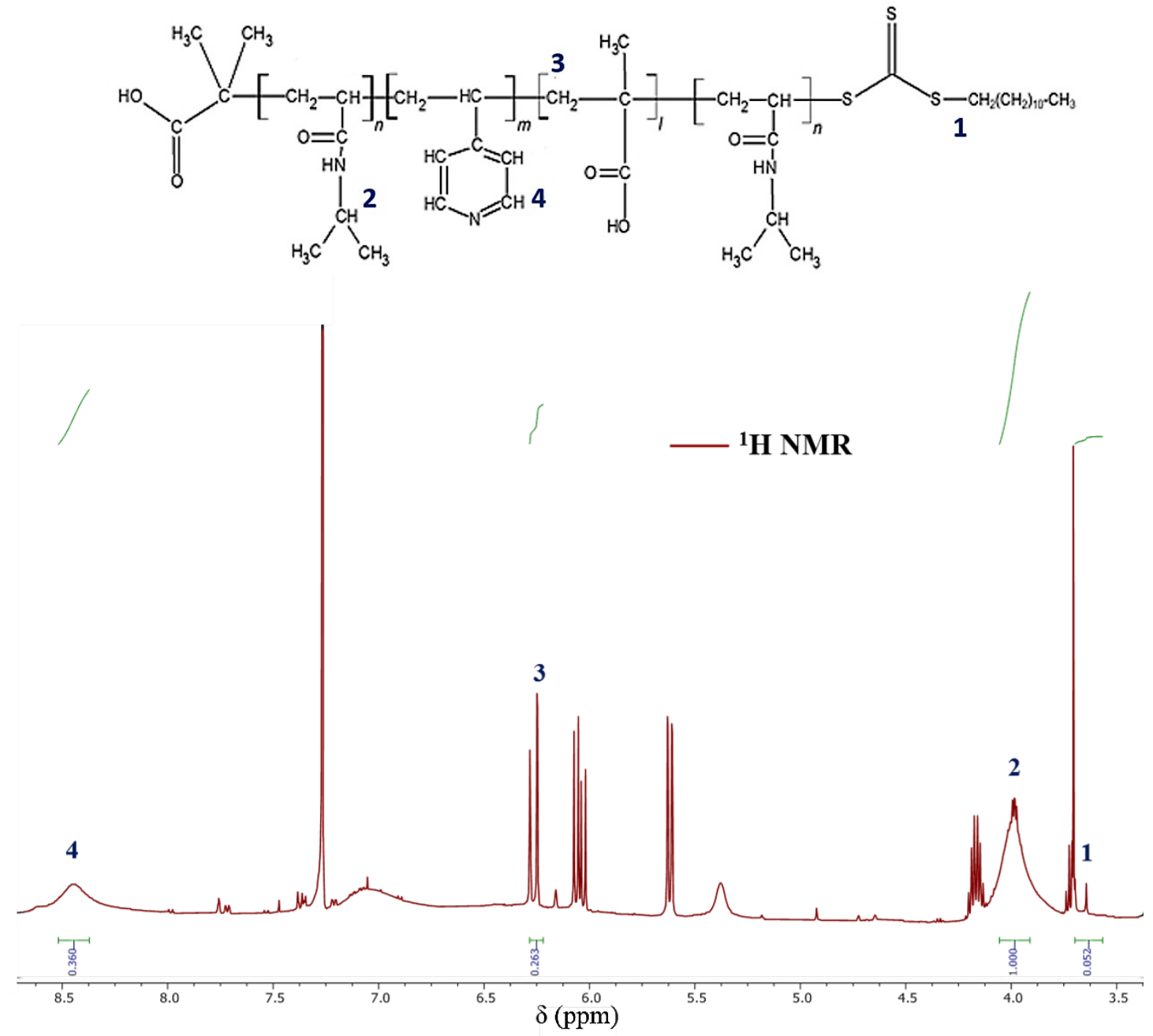

Figure S1. ${ }^{1} H$ NMR Spectra for PNIPAM-based copolymer showing traces of NIPAM, MAA, and $V P$ in $\mathrm{CDCl}_{3}$. The chemical structure represents the copolymer chain arbitrary mole fraction for NIPAM, VP, and MAA, respectively. 
The structural composition of the synthesized copolymer was affirmed by the 1H-NMR spectroscopy using a Bruker Varian UnityINOVA $500 \mathrm{NMR}$ at $500 \mathrm{MHz}$ for hydrogen nuclei. $\mathrm{CDCl}_{3}$ was used to dissolve the lyophilized polymer powder. Tetramethylsilane $(\delta=0.00 \mathrm{ppm})$ was used as $\delta$-scale reference. All the chemical shifts and areas under the peaks were observed and analyzed in MNOVA 14.10 software. The $\delta(3.64 \mathrm{ppm})$ at peak $\mathbf{1}$ due to $\left[\left(-\mathrm{S}-\mathrm{C}_{2}-\mathrm{CH}_{2}\right)_{10} \mathrm{CH}_{3}\right)$ proton] is attributed to the $\mathrm{Z}$ group of RAFT agents (DDMAT) ${ }^{13}$ The $\delta(4.0 \mathrm{ppm})$ at peak 2 can be attributed to the methyl protons from NIPAM. ${ }^{14}$ The $\delta(6.25 \mathrm{ppm})$ at peak $3\left[-\mathrm{CH}_{2}\right]$ is attributed to MAA. ${ }^{15-17}$ The $\delta(8.5 \mathrm{ppm})$ at peak 4 is from VP. ${ }^{13}$

The molar ratio between functional monomer and NIPAM can be calculated via equation (1) below:

$$
\frac{\text { Functional Monomer }(\mathrm{Mol})}{\text { NIPAM }(\mathrm{Mol})}=\frac{\frac{A_{1}}{\text { No.of Proton } / \mathrm{s}}}{\frac{A_{2}}{\text { No. of Proton } / \mathrm{s}}}
$$

Using equation (1), 4-VP: NIPAM is calculated. Where $A_{1}$ is the area of aromatic protons at 8.5 $\mathrm{ppm}, \mathrm{A}_{2}$ is the area of methine protons of isopropyl group at $4.0 \mathrm{ppm}$.

$$
\frac{4-V P(M o l)}{\operatorname{NIPAM}(\mathrm{Mol})}=\frac{\frac{0.360}{2}}{\frac{1.00}{1}}=13.68: 76
$$

Equation (1) can also be utilized to estimate the molar ratio between NIPAM and DDMAT. The $\mathrm{A}_{2}$ is the area of aromatic protons at $3.64 \mathrm{ppm}, \mathrm{A}_{1}$ is the area of methine protons of isopropyl group at $4.0 \mathrm{ppm}$.

$$
\frac{\operatorname{NIPAM}(\mathrm{Mol})}{\operatorname{DDMAT}(\mathrm{Mol})}=\frac{\frac{1.00}{1}}{\frac{0.052}{4}}=76: 0.988
$$




\section{XPS Analysis (N1s, S2p, and C1s spectra)}

\section{N1s Spectra Analysis}

The N1s band indicates the presence of various nitrogen-containing species in the PNIPAM-based copolymer. The peak $\mathrm{N}_{0}(392.5 \mathrm{eV})$ may arise from the chemical interaction between the chromium ions and the protonated amine groups. ${ }^{18,19}$ The presence of chromium signature suggests the existence of trace amounts of chromium on our gold surfaces due to possible contamination during thermal evaporation. The $\mathrm{N}_{1}(395.1 \mathrm{eV})$ peak may be attributed to the acid dissociation behavior of VP, cleaving the acid-base crosslinks between MAA and VP after chelation. ${ }^{20,21}$ The $\mathrm{N}_{2}(395.8$ $-396.4 \mathrm{eV}$ ) peak primarily corresponds to the chemisorbed nitrogen on the gold surface, which correlates to the attached polymer chain coverage. ${ }^{22}$ The $\mathrm{N}_{3}(396.5-397.5 \mathrm{eV})$ band is due to the specific interaction between the amine and other oxygen-containing groups in the copolymer chains. ${ }^{20,22}$ The $\mathrm{N}_{4}(398.2-398.7 \mathrm{eV})$ band is assigned to the neutral nitrogen in the amine groups in the pyridine rings and PNIPAM. ${ }^{23}$ The pyridinium group is associated with an $\mathrm{N}_{5}(400.3 \mathrm{eV})$ peak. $^{23}$ 
Table S1: The N1s spectra for Bare gold and PNIPAM-MAA-VP polymer samples with and without exposure of TCEP during grafting to the gold surface for long (30 mins) and short (20 secs) duration of time.

\begin{tabular}{|c|c|c|c|c|c|c|}
\hline \multicolumn{7}{|c|}{$\underline{\text { N1s Spectra }}$} \\
\hline \multicolumn{7}{|c|}{ Bare Gold (Figure S(c)) } \\
\hline Peaks & $N_{0}$ & $N_{1}$ & $\mathrm{~N}_{2}$ & $N_{3}$ & $N_{4}$ & $N_{5}(401.4 e V)$ \\
\hline Bonds & $\begin{array}{l}\text { Cr-Amine } \\
\text { interaction }\end{array}$ & $\begin{array}{c}\text { Acid dissociation } \\
\text { of VP }\end{array}$ & $\begin{array}{c}\text { Chemisorbed Nitrogen } \\
\text { at } \mathrm{Au} / \mathrm{Cr} \text { interface }\end{array}$ & $\begin{array}{c}\text { Amine- } \\
\text { oxygen } \\
\text { interaction } \\
\end{array}$ & $\begin{array}{l}\text { Neutral } \\
\text { nitrogen }\end{array}$ & $\begin{array}{c}\text { Protonated } \\
\text { pyridinium } \\
\text { ions }\end{array}$ \\
\hline $\mathrm{At} \%$ & NA & NA & NA & NA & NA & $100 \pm 27$ \\
\hline $\begin{array}{c}\text { FWHM } \\
(\mathrm{eV})\end{array}$ & NA & NA & NA & NA & NA & 4.92 \\
\hline \multicolumn{7}{|c|}{ PNIPAM copolymer coated gold samples without TCEP for 30 mins (Figure 2(b)) } \\
\hline Peaks & $N_{0}(392.5 \mathrm{eV})$ & $N_{1}$ & $\mathrm{~N}_{2}(396.5 \mathrm{eV})$ & $N_{3}$ & $\mathrm{~N}_{4}(398.2 \mathrm{eV})$ & $N_{5}$ \\
\hline Bonds & $\begin{array}{l}\text { Cr-Amine } \\
\text { interaction }\end{array}$ & $\begin{array}{c}\text { Acid dissociation } \\
\text { of VP }\end{array}$ & $\begin{array}{c}\text { Chemisorbed Nitrogen } \\
\text { at } \mathrm{Au}\end{array}$ & $\begin{array}{c}\text { Amine- } \\
\text { oxygen } \\
\text { interaction }\end{array}$ & $\begin{array}{l}\text { Neutral } \\
\text { nitrogen }\end{array}$ & $\begin{array}{c}\text { Protonated } \\
\text { pyridinium } \\
\text { ions }\end{array}$ \\
\hline $\mathrm{At} \%$ & $3.9 \pm 3.7$ & NA & $71.3 \pm 9.6$ & NA & $24.8 \pm .8$ & NA \\
\hline $\begin{array}{c}\text { FWHM } \\
(\mathrm{eV})\end{array}$ & 1.92 & NA & 3.00 & NA & 3.21 & NA \\
\hline
\end{tabular}

PNIPAM copolymer coated gold samples without TCEP for 20 secs (Figure 2(c))

\begin{tabular}{ccccccc}
\hline Peaks & $\mathrm{N}_{\mathbf{0}}$ & $\mathrm{N}_{\mathbf{1}}(\mathbf{3 9 5 . 1 e V )}$ & $\mathrm{N}_{\mathbf{2}}(\mathbf{3 9 6 . 3 e V})$ & $\mathrm{N}_{3}$ & $\mathrm{~N}_{4}$ & $\mathrm{~N}_{5}$ \\
\hline Bonds & $\begin{array}{c}\text { Cr-Amine } \\
\text { interaction }\end{array}$ & $\begin{array}{c}\text { Acid dissociation } \\
\text { of VP }\end{array}$ & $\begin{array}{c}\text { Chemisorbed Nitrogen } \\
\text { at Au }\end{array}$ & $\begin{array}{c}\text { Amine- } \\
\text { oxygen } \\
\text { interaction }\end{array}$ & $\begin{array}{c}\text { Neutral } \\
\text { nitrogen }\end{array}$ & $\begin{array}{c}\text { Protonated } \\
\text { pyridinium } \\
\text { ions }\end{array}$ \\
\hline At $\%$ & NA & $16.1 \pm 7.1$ & $83.9 \pm 7.1$ & NA & NA & NA \\
\hline $\begin{array}{c}\text { FWHM } \\
(\mathrm{eV})\end{array}$ & NA & 2.07 & 2.74 & NA & NA & NA \\
\hline
\end{tabular}

PNIPAM copolymer coated gold samples with TCEP for 30 mins (Figure 2(d))

\begin{tabular}{|c|c|c|c|c|c|c|}
\hline Peaks & $N_{0}$ & $N_{1}$ & $N_{2}(395.8 \mathrm{eV})$ & $N_{3}(397 e V)$ & $\mathrm{N}_{4}(398.2 \mathrm{eV})$ & $N_{5}$ \\
\hline Bonds & $\begin{array}{l}\text { Cr-Amine } \\
\text { interaction }\end{array}$ & $\begin{array}{c}\text { Acid dissociation } \\
\text { of VP }\end{array}$ & $\begin{array}{c}\text { Chemisorbed Nitrogen } \\
\text { at } \mathrm{Au}\end{array}$ & $\begin{array}{c}\text { Amine- } \\
\text { oxygen } \\
\text { interaction }\end{array}$ & $\begin{array}{l}\text { Neutral } \\
\text { nitrogen }\end{array}$ & $\begin{array}{c}\text { Protonated } \\
\text { pyridinium } \\
\text { ions } \\
\end{array}$ \\
\hline $\mathrm{At} \%$ & NA & NA & $36.4 \pm 8.1$ & $29.6 \pm 7.5$ & $34 \pm 8.3$ & NA \\
\hline $\begin{array}{c}\text { FWHM } \\
(\mathrm{eV})\end{array}$ & NA & NA & 1.90 & 1.60 & 2.00 & NA \\
\hline
\end{tabular}

PNIPAM-MAA-VP coated gold samples with TCEP for 20 secs (Figure 2(e))

\begin{tabular}{|c|c|c|c|c|c|c|}
\hline Peaks & $N_{0}$ & $\overline{N_{1}}$ & $\mathrm{~N}_{2}$ & $N_{3}(396.6 \mathrm{eV})$ & $\mathrm{N}_{4}(398.7 \mathrm{eV})$ & $N_{5}(400.3 \mathrm{eV})$ \\
\hline Bonds & $\begin{array}{l}\text { Cr-Amine } \\
\text { interaction }\end{array}$ & $\begin{array}{c}\text { Acid dissociation } \\
\text { of VP }\end{array}$ & $\begin{array}{c}\text { Chemisorbed Nitrogen } \\
\text { at } \mathrm{Au}\end{array}$ & $\begin{array}{c}\text { Amine- } \\
\text { oxygen } \\
\text { interaction }\end{array}$ & $\begin{array}{l}\text { Neutral } \\
\text { nitrogen }\end{array}$ & $\begin{array}{l}\text { Protonated } \\
\text { pyridinium } \\
\quad \text { ions }\end{array}$ \\
\hline $\mathrm{At} \%$ & NA & NA & NA & $13.8 \pm 10.2$ & $57.8 \pm 22$ & $18.9 \pm 20$ \\
\hline $\begin{array}{c}\text { FWHM } \\
(\mathrm{eV})\end{array}$ & NA & NA & NA & 1.46 & 2.20 & 1.93 \\
\hline
\end{tabular}




\section{S2p Spectra Analysis}

The $\mathrm{S}_{1}(162.6-162.9 \mathrm{eV})$ and $\mathrm{S}_{2}(163.7-164.2 \mathrm{eV})$ peaks are associated with the chemisorbed and physisorbed thiol groups at the gold surface, respectively. ${ }^{24}$ The $\mathrm{S}_{0}(160.7-161 \mathrm{eV})$ peaks also indicate chemisorbed thiol binding but at alternative adsorption sites such as defect sites and non-planar regions with short chain length thiol precursors. ${ }^{25,26}$ The $\mathrm{S}_{3}(165.2 \mathrm{eV})$ peak vibration arises from the hydrophobic (-S-C-S-) covalent bond from the adsorption of trithiocarbonate of the RAFT chain transfer agent. $5,8,27,28$ The $\mathrm{S}_{5}(168 \mathrm{eV})$ peak indicates the presence of sulfur amine complexes which has a contribution from the presence of both N3 and N5, ${ }^{25,29}$ and the $\mathrm{S}_{4}$ $(165.6-166.2 \mathrm{eV})$ peak indicates sulfur-oxide complexes due to unwanted oxidation of disulfide species. $^{25}$ 
Table S2: The S2p spectra for Bare gold and PNIPAM-MAA-VP polymer samples with and without exposure of TCEP during grafting to the gold surface for long (30 mins) and short (20 secs) duration of time.

\section{$\underline{\text { S2p Spectra }}$}

\section{Bare Au (Figure S(e))}

\begin{tabular}{|c|c|c|c|c|c|c|}
\hline Peaks & $S_{0}$ & $S_{1}$ & $S_{2}$ & $S_{3}$ & $S_{4}$ & $S_{5}$ \\
\hline Bonds & $\begin{array}{c}\text { Atomically } \\
\text { adsorbed sulfur }\end{array}$ & $\begin{array}{c}\text { Chemisorbed } \\
\text { thiols }\end{array}$ & $\begin{array}{l}\text { Physiosorbed thiols/ } \\
\text { weakly bond thiol }\end{array}$ & $\begin{array}{l}\text { unbound } \\
\text { alkane thiol }\end{array}$ & $\begin{array}{l}\text { Oxidized sulfur } \\
C(S-O) \text { bond }\end{array}$ & $\begin{array}{c}\mathrm{S} \text { atom in free } \\
\text { molecule }\end{array}$ \\
\hline $\mathrm{At} \%$ & NA & NA & NA & NA & NA & NA \\
\hline $\begin{array}{c}\text { FWHM } \\
(\mathrm{eV})\end{array}$ & NA & NA & NA & NA & NA & NA \\
\hline
\end{tabular}

PNIPAM-MAA-VP coated Au samples without TCEP for 30 mins (Figure 2(g))

\begin{tabular}{ccccccc}
\hline Peaks & $\boldsymbol{S}_{\boldsymbol{0}}(\mathbf{1 6 0 . 7 e V})$ & $\boldsymbol{S}_{\mathbf{1}}(\mathbf{1 6 2 . 9 e V )}$ & $\boldsymbol{S}_{2}(\mathbf{1 6 4 . 2 e V})$ & $\boldsymbol{S}_{3}(\mathbf{1 6 5 . 2 e V})$ & $\boldsymbol{S}_{4}(\mathbf{1 6 6 . 2 e V})$ & $\boldsymbol{S}_{5}$ \\
\hline Bonds & $\begin{array}{c}\text { Atomically } \\
\text { adsorbed sulfur }\end{array}$ & $\begin{array}{c}\text { Chemisorbed } \\
\text { thiols }\end{array}$ & $\begin{array}{c}\text { Physiosorbed thiols/ } \\
\text { weakly bond thiol }\end{array}$ & $\begin{array}{c}\text { unbound } \\
\text { alkane thiol }\end{array}$ & $\begin{array}{c}\text { Oxidized sulfur } \\
\text { C(S-O) bond }\end{array}$ & $\begin{array}{c}\text { S atom in free } \\
\text { molecule }\end{array}$ \\
\hline $\begin{array}{c}\mathrm{At} \% \\
\mathrm{FWHM} \\
(\mathrm{eV})\end{array}$ & $8.0 \pm 6.4$ & $6.2 \pm 1.6$ & $25.6 \pm 9.6$ & $15.8 \pm 6.5$ & $44.4 \pm .11 .2$ & NA \\
\hline
\end{tabular}

PNIPAM-MAA-VP coated Au samples without TCEP for 20 secs (Figure 2(h))

\begin{tabular}{ccccccc}
\hline Peaks & $\boldsymbol{S}_{\boldsymbol{0}}$ & $\boldsymbol{S}_{\mathbf{1}}(\mathbf{1 6 2 . 6 e V )}$ & $\boldsymbol{S}_{\mathbf{2}}(\mathbf{1 6 4 e V})$ & $\boldsymbol{S}_{\mathbf{3}}$ & $\boldsymbol{S}_{4}(\mathbf{1 6 5 . 6 e V})$ & $\boldsymbol{S}_{5}$ \\
\hline Bonds & $\begin{array}{c}\text { Atomically } \\
\text { adsorbed sulfur }\end{array}$ & $\begin{array}{c}\text { Chemisorbed } \\
\text { thiols }\end{array}$ & $\begin{array}{c}\text { Physiosorbed thiols/ } \\
\text { weakly bond thiol }\end{array}$ & $\begin{array}{c}\text { unbound } \\
\text { alkane thiol }\end{array}$ & $\begin{array}{c}\text { Oxidized sulfur } \\
\text { C(S-O) bond }\end{array}$ & $\begin{array}{c}\text { S atom in free } \\
\text { molecule }\end{array}$ \\
\hline At\% & NA & $6.2 \pm 5.3$ & $45 \pm 9.5$ & NA & $48.8 \pm 9.7$ & NA \\
\hline $\begin{array}{c}\text { FWHM } \\
(\mathrm{eV})\end{array}$ & NA & 1.33 & 2.00 & NA & 2.11 & NA \\
\hline
\end{tabular}

PNIPAM-MAA-VP coated Au samples with TCEP for 30 mins (Figure 2(i))

\begin{tabular}{ccccccc}
\hline Peaks & $\boldsymbol{S}_{\boldsymbol{0}}$ & $\boldsymbol{S}_{\boldsymbol{1}}$ & $\boldsymbol{S}_{\mathbf{2}}(\mathbf{1 6 3 . 8 e V )}$ & $\boldsymbol{S}_{\mathbf{3}}$ & $\boldsymbol{S}_{4}(\mathbf{1 6 5 . 7 e V )}$ & $\boldsymbol{S}_{5}$ \\
\hline Bonds & $\begin{array}{c}\text { Atomically } \\
\text { adsorbed sulfur }\end{array}$ & $\begin{array}{c}\text { Chemisorbed } \\
\text { thiols }\end{array}$ & $\begin{array}{c}\text { Physiosorbed thiols/ } \\
\text { weakly bond thiol }\end{array}$ & $\begin{array}{c}\text { unbound } \\
\text { alkane thiol }\end{array}$ & $\begin{array}{c}\text { Oxidized sulfur } \\
\text { C(S-O) bond }\end{array}$ & $\begin{array}{c}\text { S atom in free } \\
\text { molecule }\end{array}$ \\
\hline $\begin{array}{c}\text { At } \% \\
\text { FWHM } \\
(\mathrm{eV})\end{array}$ & NA & NA & $9.2 \pm 15.6$ & NA & $90.8 \pm 15.6$ & NA \\
\hline
\end{tabular}

PNIPAM-MAA-VP coated Au samples with TCEP for 20 secs (Figure 2(j))

\begin{tabular}{ccccccc}
\hline Peaks & $\boldsymbol{S}_{\mathbf{0}}(\mathbf{1 6 1 . 0 e V})$ & $\boldsymbol{S}_{\mathbf{1}}(\mathbf{1 6 2 . 8 e V})$ & $\boldsymbol{S}_{\mathbf{2}}$ & $\boldsymbol{S}_{\mathbf{3}}$ & $\boldsymbol{S}_{4}(\mathbf{1 6 5 . 8 e V})$ & $\boldsymbol{S}_{5}(\mathbf{1 6 8 e V})$ \\
\hline Bonds & $\begin{array}{c}\text { Atomically } \\
\text { adsorbed sulfur }\end{array}$ & $\begin{array}{c}\text { Chemisorbed } \\
\text { thiols }\end{array}$ & $\begin{array}{c}\text { Physiosorbed thiols/ } \\
\text { weakly bond thiol }\end{array}$ & $\begin{array}{c}\text { unbound } \\
\text { alkane thiol }\end{array}$ & $\begin{array}{c}\text { Oxidized sulfur } \\
\text { C(S-O) bond }\end{array}$ & $\begin{array}{c}\text { S atom in free } \\
\text { molecule }\end{array}$ \\
\hline At\% & $14.1 \pm 4.7$ & $21.2 \pm 5.1$ & NA & NA & $31.6 \pm 4.5$ & $33.1 \pm 5.0$ \\
\hline $\begin{array}{c}\text { FWHM } \\
(\mathrm{eV})\end{array}$ & 2.13 & 2.40 & NA & NA & 1.99 & 2.19 \\
\hline
\end{tabular}




\section{C1s Spectra of the PNIPAM-based Copolymer Coated on Gold Surface}

The $\mathrm{C}_{1}$ peak at the Au surface arises from mild oxidation of adventitious carbon contained various hydrocarbon species at the gold surface after cleaning with ethanol. ${ }^{30}$ The peak at $\mathrm{C}_{2}$ occurs in PNIPAM-based copolymer coated on gold samples primarily due to $\mathrm{C}=\mathrm{O}$ groups of PNIPAM attached with the alkyl carbon chain of the copolymer backbone. ${ }^{30}$ The $\mathrm{C}_{0}$ peak is attributed to the $\mathrm{C}-\mathrm{C}$ bond arising from the polymer chain scission effect. ${ }^{30}$ Weak bands designated to $\mathrm{C}_{3}$ peak is attributed to the $\mathrm{C}-\mathrm{H}$ group arising mainly from pyridine rings of VP. ${ }^{23,31}$ The carbon species at the copolymer backbone, which correspond to carbon bound only to carbon or hydrogen $(\underline{\mathrm{C}}-(\mathrm{C}, \mathrm{H}))$, has the $\mathrm{C}_{4}$ peak that occurs due to the PNIPAM $\left(\mathrm{CH}_{2}\right)$ backbone along with the presence of $\mathrm{C}=\mathrm{O}$ or $\mathrm{C}-\mathrm{N}$ group. ${ }^{23,31,32}$ The $\mathrm{C}_{5}$ peak is attributed to carbon bound to a carbon, which is attached to two oxygens $(\underline{\mathrm{C}}-(\mathrm{COO})$ assigned to MAA. Zhai et al. showed that the VP copolymerized with PNIPAM backbone have similar $\mathrm{C}_{4}$, and $\mathrm{C}_{5}$ peaks have a contribution from both PNIPAM and VP side chains. ${ }^{23}$

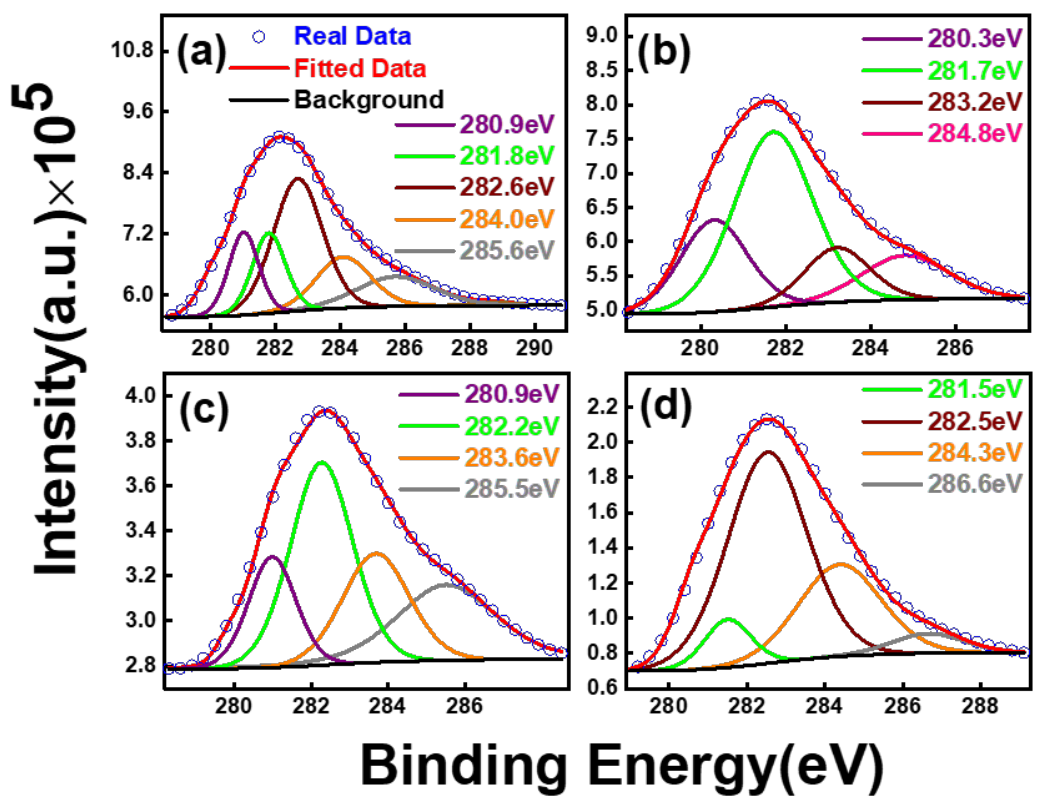

Figure S2. The XPS spectra of C1s of the PNIPAM-based copolymer coated on gold surfaces. The figure shows the spectra for the polymer coated without TCEP for 30 mins (a); without TCEP for $20 \mathrm{sec}$ (b); with TCEP for 30 mins (c); and with TCEP for $20 \mathrm{sec}$ (d). The C1s spectra mainly emphasizes on $(\mathrm{N}-\underline{\mathrm{C}}=\mathrm{O} / \mathrm{O}-\underline{\mathrm{C}}=\mathrm{O})$ functional moieties of PNIPAM and MAA. Legends: raw data (blue circle), fitted data (red), and background (black), $C_{0}: 280.3-280.9 \mathrm{eV}$ (purple); $C_{1}: 281.5-282.2 \mathrm{eV}$ (green); $C_{2}: 282.5-283.2 \mathrm{eV}$ (wine); $C_{3}: 283.5-284.3 \mathrm{eV}$ (orange); $C_{4}: 284.8-285.3 \mathrm{eV}$ (pink); $C_{5}: 285.5-287.2 \mathrm{eV}$ (gray). 
Table S3: The C1s spectra for Bare gold and the copolymer samples with and without exposure of TCEP during grafting to the gold surface for long (30 mins) and short (20 secs) duration of time.

\begin{tabular}{ccccccc}
\hline \multicolumn{7}{c}{ C1s Spectra } \\
\hline \multicolumn{7}{c}{ Bare Au (Figure S(a)) } \\
\hline Peaks & $\boldsymbol{C}_{\boldsymbol{0}}$ & $\boldsymbol{C}_{\boldsymbol{l}}$ & $\boldsymbol{C}_{2}(\mathbf{2 8 3 . 2 e V})$ & $\boldsymbol{C}_{3}$ & $\boldsymbol{C}_{4}(\mathbf{2 8 4 . 8 e V})$ & $\boldsymbol{C}_{5}(\mathbf{2 8 6 . 6 e V})$ \\
\hline Bonds & $C-C$ & $C=O$ & $C-H$ & $C-H$ & $(C-(C, H))$ & $\begin{array}{c}C-O H / C- \\
(C O O)\end{array}$ \\
\hline At $\%$ & NA & NA & $74.62 \pm 4.63$ & NA & $18.61 \pm 3.64$ & $6.77 \pm 3.88$ \\
\hline FWHM $(\mathrm{eV})$ & NA & NA & 2.14 & NA & 1.60 & 1.80 \\
\hline
\end{tabular}

PNIPAM-MAA-VP coated Au samples without TCEP for 30 mins (Figure S(a))

\begin{tabular}{ccccccc}
\hline Peaks & $\boldsymbol{C}_{\boldsymbol{o}}(\mathbf{2 8 0 . 9 e V )}$ & $\boldsymbol{C}_{\boldsymbol{1}}(\mathbf{2 8 1 . 8 e V})$ & $\boldsymbol{C}_{2}(\mathbf{2 8 2 . 6 e V})$ & $\boldsymbol{C}_{3}(\mathbf{2 8 4 . 0 e V})$ & $\boldsymbol{C}_{4}$ & $\boldsymbol{C}_{5}(\mathbf{2 8 5 . 6 e V})$ \\
\hline Bonds & $C-C$ & $C=O$ & $C-H$ & $C-H$ & $(C-(C, H))$ & $\begin{array}{c}C_{-O H}-C_{-}- \\
(C O O)\end{array}$ \\
\hline $\mathrm{At} \%$ & $7.8 \pm 0.27$ & $28.1 \pm 0.43$ & $35.5 \pm 0.48$ & $16.0 \pm 0.68$ & $\mathrm{NA}$ & $12.6 \pm 0.5$ \\
\hline FWHM $(\mathrm{eV})$ & 1.16 & 1.20 & 1.79 & 1.98 & $\mathrm{NA}$ & 2.2 \\
\hline
\end{tabular}

PNIPAM-MAA-VP coated Au samples without TCEP for 20 secs (Figure S(c) )

\begin{tabular}{ccccccc}
\hline Peaks & $\boldsymbol{C}_{\boldsymbol{o}}(\mathbf{2 8 0 . 3 e V})$ & $\boldsymbol{C}_{\boldsymbol{l}}(\mathbf{2 8 1 . 7 e V})$ & $\boldsymbol{C}_{2}(\mathbf{2 8 3 . 2 e V})$ & $\boldsymbol{C}_{3}$ & $\boldsymbol{C}_{4}(\mathbf{2 8 4 . 8 e V})$ & $\boldsymbol{C}_{\boldsymbol{5}}$ \\
\hline Bonds & $C-C$ & $C=O$ & $C-H$ & $C-H$ & $(C-(C, H))$ & $\begin{array}{c}C-O H / C_{-} \\
(C O O)\end{array}$ \\
\hline $\mathrm{At} \%$ & $22.6 \pm 0.47$ & $50.3 \pm 0.57$ & $13.0 \pm 0.47$ & NA & $14.1 \pm 0.5$ & NA \\
\hline FWHM $(\mathrm{eV})$ & 1.85 & 2.16 & 1.80 & NA & 2.40 & NA \\
\hline
\end{tabular}

PNIPAM-MAA-VP coated Au samples with TCEP for 30 mins (Figure S(d))

\begin{tabular}{ccccccc}
\hline Peaks & $\boldsymbol{C}_{\boldsymbol{o}}(\mathbf{2 8 0 . 9 e V})$ & $\boldsymbol{C}_{\boldsymbol{l}}(\mathbf{2 8 2 . 2 e V})$ & $\boldsymbol{C}_{2}(\mathbf{2 8 3 . 6 e V})$ & $\boldsymbol{C}_{3}$ & $\boldsymbol{C}_{4}$ & $\boldsymbol{C}_{5}(\mathbf{2 8 5 . 5 e V})$ \\
\hline Bonds & $C-C$ & $C=O$ & $C-H$ & $C-H$ & $(C-(C, H))$ & $\begin{array}{c}C-O H / C- \\
(C O O)\end{array}$ \\
\hline At $\%$ & $20.5 \pm 0.8$ & $38.4 \pm 1.0$ & $22.1 \pm 1.0$ & NA & NA & $12.6 \pm 0.5$ \\
\hline FWHM $(\mathrm{eV})$ & 1.44 & 1.90 & 2.04 & NA & NA & 2.2 \\
\hline
\end{tabular}

PNIPAM-MAA-VP coated Au samples with TCEP for 20 secs (Figure $\mathrm{S}$ (e))

\begin{tabular}{ccccccc}
\hline Peaks & $\boldsymbol{C}_{\boldsymbol{o}}$ & $\boldsymbol{C}_{\boldsymbol{l}}(\mathbf{2 8 1 . 5 e V})$ & $\boldsymbol{C}_{\boldsymbol{2}}(\mathbf{2 8 2 . 5 e V})$ & $\boldsymbol{C}_{3}(\mathbf{2 8 4 . 3 e V})$ & $\boldsymbol{C}_{4}$ & $\boldsymbol{C}_{5}(\mathbf{2 8 6 . 6 e V})$ \\
\hline Bonds & $C-C$ & $C=O$ & $C-H$ & $C-H$ & $(C-(C, H))$ & $\begin{array}{c}C-O H / C- \\
(C O O)\end{array}$ \\
\hline At\% & NA & $7.4 \pm 0.4$ & $55.6 \pm 0.6$ & $32.3 \pm 0.6$ & NA & $4.7 \pm 0.4$ \\
\hline FWHM $(\mathrm{eV})$ & NA & 1.40 & 2.40 & 2.49 & NA & 2.17 \\
\hline
\end{tabular}




\section{Bare Au surface C1s, N1s, and S2p spectra from XPS:}

Figure S3 shows the XPS spectra of the bare gold electrode. The $\mathrm{C} 1 \mathrm{~s}$ at gold arises due to hydrocarbon species present at the surface from the interaction with air. The $\mathrm{C}_{2}(283.2 \mathrm{eV})$ and $\mathrm{C}_{4}$ $(284.8 \mathrm{eV})$ peaks at bare $\mathrm{Au}$ surface is attributed to $\mathrm{C}-\mathrm{H}$ bond from hydrocarbon complexes comprising of adventitious carbons. ${ }^{33}$ The $\mathrm{C}_{5}(286.6 \mathrm{~V})$ peak at the Au surface arises from mild oxidation of adventitious carbon (C-O) species at the gold surface after cleaning with ethanol..$^{23,30}$ The N1s spectra are associated with molecular nitrogen $\left(\mathrm{N}_{4}: 401.4 \mathrm{eV}\right)$ trapped beneath the gold surface along with adventitious carbon species. ${ }^{22}$ No traceable S2P peaks were present in the bare gold surface.

\section{Gold Surface}
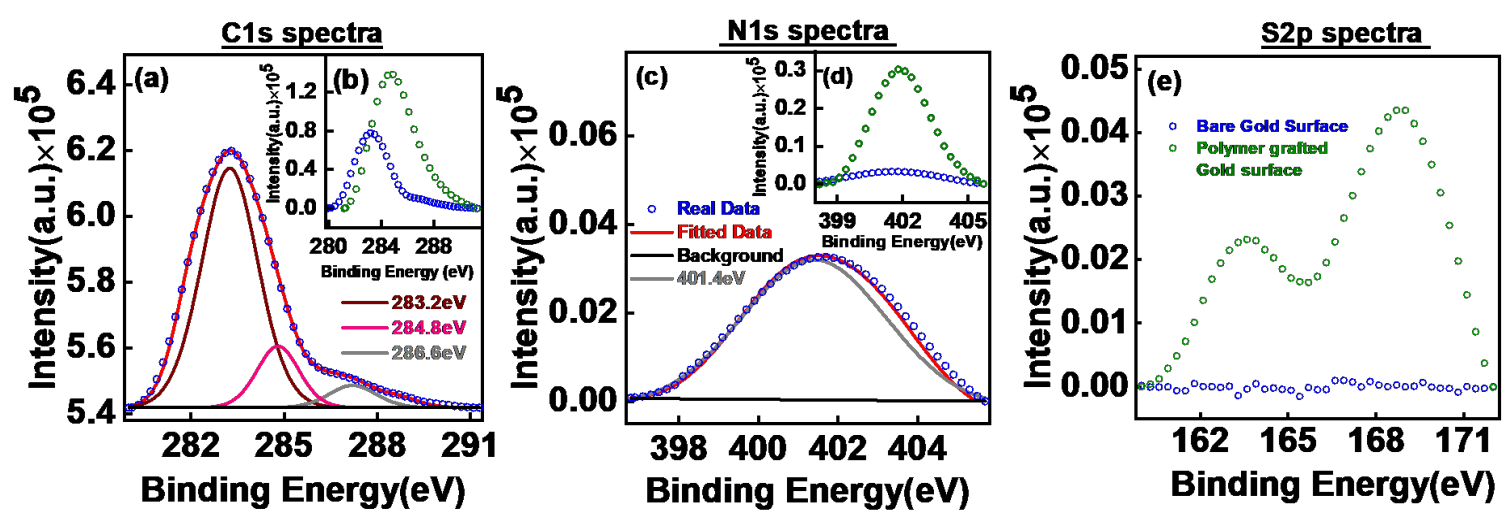

Figure S3: $C 1 s(a \& b), N 1 s(c \& d)$, and S2p (e) XPS spectra for bare gold electrode. The C1s spectra shows the presence of adventitious carbon on the gold surface as impurity, and the N1s spectra shows interaction of nitrogen with carbon and other impurities. The $S 2 p$ spectra reveals the absence of sulfur species on the bare gold surface (blue circles) compared to the polymer modified gold electrode (green circles). Legends: The C1s, N1s, and S2p spectra curves contain raw data (blue circle), fitted data (red), and background (black); $C_{2}: 282.5-283.2 \mathrm{eV}$ (wine); $C_{4}: 284.8-285.3 \mathrm{eV}$ (pink); $C_{5}: 285.5-286.6 \mathrm{eV}$ (gray); $N_{5}: 401.4 e V$ (gray); 


\section{The Effects of Anions on the Stability of the PNIPAM-MAA-VP Copolymer}


Figure S4: The schematic representation of the interaction of PNIPAM based polymers in water. (a) hydrophobic hydration via forming water cages along with the hydrocarbons; and (b) hydrogen bonding between a water molecule and amide moieties. After exposure to the salt solution, (c) the anions demonstrate direct binding with the amide group from PNIPAM. Such phenomenon is prevalent in highly polarizing, chaotropic anions at low concentrations. (d) The hydrogen bonding between amide and adjacent water molecules are destabilized in the presence of hydrating kosmotropic anions. This exhibits salting-out effect during exposure toward hydrated polymer chains and partially or fully dehydrate the polymer, which results in a decrease in LCST. Here the $A^{-}$(Blue) is representing arbitrary anion. The polarizing conditions of atoms within the interacting groups are represented by $\delta^{-}$or $\delta^{-}$depending on the polarized state. ${ }^{34-36}$ 


\section{Electrochemical Impedance Spectroscopy (EIS) Analysis of Polymer Grafting to the Electrode}

Table S4: EIS Circuit fitting parameters for PNIPAM-based copolymers grafted to the electrode at a concentration of $0.05 \mu \mathrm{g} / \mathrm{ml}$ in D.I water in the presence of TCEP.

\section{Circuit Parameters}

\begin{tabular}{|c|c|c|c|c|c|}
\hline \multicolumn{6}{|c|}{$(0.5 \mu \mathrm{g} / \mathrm{ml})$ Polymer grafting to gold electrode } \\
\hline \multirow[t]{2}{*}{ Grafting time } & $\begin{array}{l}\text { Electrolyte } \\
\text { Resistance }\end{array}$ & \multicolumn{4}{|c|}{ Gold Electrode and the polymer Interface } \\
\hline & $R_{S}(\Omega)$ & $Q_{1}\left(\mu F \cdot s^{n-1}\right)$ & $n$ & $\overline{R_{c t}(\boldsymbol{\Omega})}$ & $A_{W}\left(\Omega . s^{-0.5}\right)$ \\
\hline Bare Gold & $84.3 \pm 0.2$ & $10 \pm 3$ & $0.87 \pm 0.5$ & $40.6 \pm 1.2$ & $440 \pm 1$ \\
\hline 30 secs & $83.4 \pm 0.2$ & $4.6 \pm 0.5$ & $0.87 \pm 0.5$ & $99.4 \pm 0.7$ & $433 \pm 1$ \\
\hline $1 \mathrm{~min}$ & $86.9 \pm 0.2$ & $4.4 \pm 0.6$ & $0.85 \pm 0.5$ & $115.1 \pm 0.8$ & $493 \pm 1.2$ \\
\hline 2 mins & $86.7 \pm 0.2$ & $4.1 \pm 0.2$ & $0.87 \pm 0.5$ & $165.2 \pm 0.7$ & $489 \pm 1.2$ \\
\hline 4 mins & $83.3 \pm 0.2$ & $4.2 \pm 0.2$ & $0.87 \pm 0.5$ & $196.5 \pm 0.7$ & $484 \pm 1.3$ \\
\hline 8 mins & $85 \pm 0.2$ & $4.0 \pm 0.1$ & $0.88 \pm 0.5$ & $237.3 \pm 0.7$ & $486 \pm 1.3$ \\
\hline 16 mins & $85.7 \pm 0.2$ & $3.4 \pm 0.1$ & $0.89 \pm 0.5$ & $279.5 \pm 0.7$ & $485 \pm 1.4$ \\
\hline 32 mins & $85.7 \pm 0.2$ & $3.6 \pm 0.1$ & $0.88 \pm 0.5$ & $304.2 \pm 0.7$ & $486 \pm 1.4$ \\
\hline
\end{tabular}


Table S5: EIS Circuit fitting parameters for PNIPAM-based copolymer grafted at a concentration of $0.5 \mu \mathrm{g} / \mathrm{ml}$ in D.I. water in the presence of TCEP to the gold electrode.

\section{Circuit Parameters}

\section{$(0.05 \mu \mathrm{g} / \mathrm{ml})$ PNIPAM-MAA-VP grafting to the gold electrode}

\begin{tabular}{c|c|c|c|c|c}
\hline \multirow{2}{*}{$\begin{array}{c}\text { Grafting } \\
\text { time }\end{array}$} & $\begin{array}{c}\text { Electrolyte } \\
\text { Resistance }\end{array}$ & \multicolumn{4}{l}{ Gold Electrode and PNIPAM-MAA-VP Interface } \\
\cline { 2 - 6 } & $\boldsymbol{R}_{\boldsymbol{s}}(\boldsymbol{\Omega})$ & $\boldsymbol{Q}_{\boldsymbol{I}}\left(\boldsymbol{\mu} \boldsymbol{F} . \boldsymbol{s}^{\boldsymbol{n}-\boldsymbol{1}}\right)$ & $\boldsymbol{n}$ & $\boldsymbol{R}_{\boldsymbol{c t}}(\boldsymbol{\Omega})$ & $\boldsymbol{A}_{\boldsymbol{W}}\left(\boldsymbol{\Omega} . \boldsymbol{s}^{-\mathbf{0 . 5}}\right)$ \\
\hline Bare Gold & $84.3 \pm 0.2$ & $10 \pm 3$ & $0.87 \pm 0.5$ & $40.6 \pm 1.2$ & $440 \pm 1$ \\
\hline $30 \mathrm{secs}$ & $83.7 \pm 0.2$ & $6.3 \pm 0.9$ & $0.87 \pm 0.5$ & $78.6 \pm 0.8$ & $438 \pm 1.1$ \\
\hline 1 min & $86.5 \pm 0.2$ & $5.6 \pm 0.6$ & $0.86 \pm 0.5$ & $106.4 \pm 0.8$ & $493 \pm 1.1$ \\
\hline 2 mins & $86.5 \pm 0.2$ & $4.6 \pm 0.4$ & $0.87 \pm 0.5$ & $115.3 \pm 0.8$ & $495 \pm 1.1$ \\
\hline 4 mins & $87.6 \pm 0.2$ & $5.1 \pm 0.4$ & $0.86 \pm 0.5$ & $132 \pm 0.8$ & $497 \pm 1.1$ \\
\hline 8 mins & $88.9 \pm 0.2$ & $4.6 \pm 0.3$ & $0.86 \pm 0.5$ & $141.2 \pm 0.8$ & $508 \pm 1.1$ \\
\hline 16 mins & $89.3 \pm 0.2$ & $4.5 \pm 0.3$ & $0.86 \pm 0.5$ & $156 \pm 0.8$ & $512 \pm 1.2$ \\
\hline 32 mins & $83.2 \pm 0.2$ & $4.2 \pm 0.2$ & $0.87 \pm 0.5$ & $179 \pm 0.7$ & $485 \pm 1.2$ \\
\hline
\end{tabular}


Table S6: Surface coverage and apparent rate constant variation as a function of grafting time estimated for $0.05 \mu \mathrm{g} / \mathrm{ml}$ of PNIPAM-based copolymer grafted to the gold surface. The surface coverage and the apparent rate constant are calculated using the formulas given below the table.

Surface Coverage $\theta(t)$ and Kinetics $\left(K_{a p p}\right)$ evaluation

(0.05 $\mu \mathrm{g} / \mathrm{ml})$ PNIPAM-MAA-VP grafted to gold electrode

\begin{tabular}{|c|c|c|c|}
\hline \multirow[t]{2}{*}{ Sample } & \multirow{2}{*}{$\begin{array}{c}\begin{array}{c}\text { Charge Transfer } \\
\text { Resistance }\end{array} \\
R_{c t}(\Omega)\end{array}$} & \multicolumn{2}{|c|}{$\begin{array}{c}\text { PNIPAM-MAA-VP surface coverage and } \\
\text { kinetics (apparent rate constant) } \\
\text { calculation }\end{array}$} \\
\hline & & ${ }^{*} K_{a p p}\left(\mathrm{~cm} \cdot \mathrm{s}^{-1}\right) \times 10^{-3}$ & ${ }^{* *} \boldsymbol{\theta}(\boldsymbol{t}) \%$ \\
\hline Bare Gold & $40.6 \pm 1.2$ & $18.6 \pm 0.3$ & 0 \\
\hline 30 secs & $78.6 \pm 0.8$ & $9.6 \pm 0.06$ & $48.3 \pm 0.5$ \\
\hline $1 \mathrm{~min}$ & $106.4 \pm 0.8$ & $7.1 \pm 0.03$ & $61.8 \pm 0.4$ \\
\hline $2 \operatorname{mins}$ & $115.3 \pm 0.8$ & $6.5 \pm 0.02$ & $64.7 \pm 0.4$ \\
\hline 4 mins & $132 \pm 0.8$ & $5.7 \pm 0.02$ & $69.2 \pm 0.4$ \\
\hline 8 mins & $141.2 \pm 0.8$ & $5.3 \pm 0.01$ & $71.2 \pm 0.4$ \\
\hline 16 mins & $156 \pm 0.8$ & $4.8 \pm 0.01$ & $73.9 \pm 0.3$ \\
\hline 32 mins & $179 \pm 0.7$ & $4.2 \pm 0.01$ & $77.3 \pm 0.3$ \\
\hline & $\begin{array}{r}{ }^{*} K_{a p} \\
{ }^{* *} \boldsymbol{\theta}(\mathbf{t})=[\mathbf{1}-\end{array}$ & 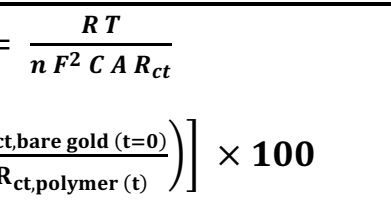 & \\
\hline
\end{tabular}


Table $\mathbf{S} 7$ Surface coverage and apparent rate constant variation as a function of grafting time estimated for $0.5 \mu \mathrm{g} / \mathrm{ml}$ of PNIPAM-MAA-VP copolymer grafted to the gold surface. All the parameters are measured using the formulas given on the table.

$\theta(t)$ Surface Coverage and Kinetics $\left(K_{\text {app }}\right)$ evaluation

(0.5 $\mathrm{\mu g} / \mathrm{ml})$ PNIPAM-MAA-VP grafted to gold electrode

\begin{tabular}{|c|c|c|c|}
\hline & $\boldsymbol{R}_{c t}(\boldsymbol{\Omega})$ & ${ }^{*} K_{a p p}\left(\mathrm{~cm} \cdot \mathrm{s}^{-1}\right) \times 10^{-3}$ & ${ }^{* *} \boldsymbol{\theta}(\boldsymbol{t}) \%$ \\
\hline $30 \mathrm{secs}$ & $99.4 \pm 0.7$ & $7.6 \pm 0.06$ & $59.1 \pm 0.8$ \\
\hline $1 \mathrm{~min}$ & $115.1 \pm 0.8$ & $6.6 \pm 0.04$ & $64.7 \pm 0.8$ \\
\hline 2 mins & $165.2 \pm 0.7$ & $4.6 \pm 0.02$ & $75.4 \pm 0.6$ \\
\hline 4 mins & $196.5 \pm 0.7$ & $3.8 \pm 0.01$ & $79.3 \pm 0.5$ \\
\hline 8 mins & $237.3 \pm 0.7$ & $3.2 \pm 0.009$ & $82.8 \pm 0.4$ \\
\hline 16 mins & $279.5 \pm 0.7$ & $2.7 \pm 0.006$ & $85.4 \pm 0.4$ \\
\hline 32 mins & $304.2 \pm 0.7$ & $2.5 \pm 0.006$ & $86.6 \pm 0.3$ \\
\hline \multicolumn{4}{|c|}{${ }^{*} K_{a p p}=\frac{R T}{n F^{2} C A R_{c t}}$} \\
\hline \multicolumn{4}{|c|}{${ }^{* *} \theta(t)=\left[1-\left(\frac{R_{\text {ct,bare gold }(t=0)}}{R_{\text {ct,polymer }(t)}}\right)\right] \times 100$} \\
\hline
\end{tabular}


Table S8 Langmuir-Freundlich isotherm model and fitting parameters of surface coverage of PNIPAMMAA-VP polymer grafted to the gold electrode with $0.05 \mu \mathrm{g} / \mathrm{ml}$ and $0.5 \mu \mathrm{g} / \mathrm{ml}$ respectively.

Surface Coverage Fitting Parameters

PNIPAM-MAA-VP grafted to the gold electrode

\begin{tabular}{l|c|c}
\multicolumn{1}{c|}{ Parameters } & \multicolumn{2}{c}{$\begin{array}{c}\text { cangmuir-Freundlich } \\
\text { isotherm model of } \\
*\end{array}$} \\
\cline { 2 - 3 } $\boldsymbol{\theta}(\boldsymbol{t}) \%$
\end{tabular}





Figure S5: The PNIPAM backbone of PNIPAM-MAA-VP which consists of (a) NIPAM monomers, (b) the VP (4-vinylpyridine) monomers, and (c) the MAA (Methacrylic acid) monomers. (d) The DDMAT is the chain transferring agent (CTA) comprises of " $R$ " and " $Z$ " group. The " $Z$ " group initiates thiol group attachment to the gold surface. 


\section{The second-order decay function for apparent rate constant variation over grafting time for two different concentration of PNIPAM-MAA-VP copolymer}

Table S9: Rate kinetics distribution of grafted PNIPAM-MAA-VP polymer to the gold electrode follows second order decay model of a two-step reaction for both concentrations $0.05 \mu \mathrm{g} / \mathrm{ml}$ and $0.5 \mu \mathrm{g} / \mathrm{ml}$. The time constants are estimated via the formula mentioned in the table below.

\begin{tabular}{|c|c|c|}
\hline \multicolumn{3}{|l|}{ Apparent Rate Constant $\left(K_{a p p}\right)$ Fitting Data } \\
\hline \multicolumn{3}{|c|}{ PNIPAM-MAA-VP polymer grafted to the gold electrode } \\
\hline \multirow[t]{2}{*}{ Parameters } & \multicolumn{2}{|c|}{$\begin{array}{l}\text { Second order exponential decay model } \\
{ }^{*} K_{a p p}\end{array}$} \\
\hline & $0.05 \mu \mathrm{g} / \mathrm{ml}$ & $0.5 \mu \mathrm{g} / \mathrm{ml}$ \\
\hline$K_{\text {offset }}:$ Offset value & $0.004 \pm\left(3.4 \times 10^{-4}\right)$ & $0.002 \pm\left(2.4 \times 10^{-4}\right)$ \\
\hline $\begin{array}{l}A_{1}: \text { Time invariant constant at less crosslinked, hydrated polymer at the gold } \\
\text { surface }\end{array}$ & $0.01 \pm\left(3.2 \times 10^{-4}\right)$ & $0.01 \pm 0.001$ \\
\hline $\begin{array}{l}K_{1}: \text { Reaction rate for diffusion at less crosslinked, more coiled polymer-gold } \\
\text { interface. }\end{array}$ & $2.7 \pm 0.2$ & $7.3 \pm 6.2$ \\
\hline${ }^{* *} \tau_{1}:$ Time Constant for less crosslinked, hydrated polymer-gold interface. & $0.2 \pm 0.01$ & $0.09 \pm 0.08$ \\
\hline $\begin{array}{l}A_{2}: \text { Time invariant constant at the highly crosslinked or cluster shaped } \\
\text { polymer-gold surface. }\end{array}$ & $0.002 \pm\left(3.2 \times 10^{-4}\right)$ & $0.005 \pm 0.001$ \\
\hline $\begin{array}{l}K_{2}: \text { Reaction rate for diffusion at highly crosslinked or cluster shaped polymer- } \\
\text { gold surface. }\end{array}$ & $0.09 \pm 0.03$ & $0.4 \pm 0.1$ \\
\hline $\begin{array}{l}{ }^{* *} \tau_{2}: \text { Time Constant for the highly crosslinked or cluster shaped polymer-gold } \\
\text { surface. }\end{array}$ & $7.7 \pm 3.1$ & $1.4 \pm 0.4$ \\
\hline$R^{2}:$ (Regression Coefficient) & 0.99918 & 0.99782 \\
\hline${ }^{*} K_{a p p}=K_{o f f s e t}+A_{1} e^{-k_{1} t}+A_{2} e^{-k_{2} t} ; * * \tau_{1 / 2}=$ & $6931 / K_{1 / 2}$ & \\
\hline
\end{tabular}


The $K_{\text {app }}$ variation over the grafting time for $0.05 \mu \mathrm{g} / \mathrm{ml}$ and $0.5 \mu \mathrm{g} / \mathrm{ml}$ follows two different diffusion-mediated processes at the interface enlisted in Table S9. Such heterogeneity is due to the simultaneous presence of untangled well-dispersed polymers as well as clustered and highly crosslinked polymers during the attachment. A polymer layer that is unable to fully or partially block the diffusion of charged species attains a $100 \%$ increment in charge transfer resistance. This is characterized by an offset value is $\mathrm{K}_{\text {offset }}$ in Table S9. The reaction rate $\mathrm{K}_{1}$ indicates faster diffusion kinetics through minimally crosslinked and highly uniform polymer arrangement which results in a lower time constant $\left(\tau_{1}\right)$ for both concentrations. Longer grafting time and high density of polymer chains during grafting may result in some anomalies. Such anomalies affect the polymer interface by grafting a highly crosslinked polymer chains, globule type polymer matrix, or partially hydrated cluster of polymer chains. Such interface leads to a much slower, or no diffusion mediated, kinetics $\left(\mathrm{K}_{2}\right)$ through the interface. Such sluggishness is the likely reason for an increased time constant $\left(\tau_{2}\right)$ for both concentrations. The overall heterogeneity, non-uniformity at the polymer-gold interface indicates $\mathrm{RC}$ time constant dispersion, which is more prevalent during longer grafting time, during maximum achievable surface coverage. ${ }^{37-43}$ 


\section{Characterizing the Target Molecule Binding to the Templated Copolymer- based Receptors}

Table S10: The EIS circuit parameters calculated after 4-NP binding at the 4-NP templated PNIPAM-MAA-VP polymer grafted to the gold electrode.

Circuit Parameters

$(0.5 \mu \mathrm{g} / \mathrm{ml})$ PNIPAM-MAA-VP (2mins) grafted to the gold electrode for $4 \mathrm{NP}$ binding

\begin{tabular}{|c|c|c|c|c|c|}
\hline \multirow{2}{*}{ Samples } & Electrolyte & \multicolumn{4}{|c|}{ PNIPAM-MAA-VP Interface } \\
\hline & $R_{s}(\Omega)$ & $Q_{1}\left(\mu F . s^{n-1}\right)$ & $n$ & $\boldsymbol{R}_{c t}(\boldsymbol{\Omega})$ & $A_{W}\left(\Omega . s^{-0.5}\right)$ \\
\hline $0 \mu \mathrm{M}$ & $86.7 \pm 0.2$ & $4.1 \pm 0.2$ & $0.87 \pm 0.5$ & $166 \pm 0.7$ & $489 \pm 1.2$ \\
\hline $1 \mu \mathrm{M}$ & $86.9 \pm 0.2$ & $3.6 \pm 0.2$ & $0.90 \pm 0.5$ & $180.5 \pm 0.6$ & $453 \pm 1.0$ \\
\hline $5 \mu \mathrm{M}$ & $88.7 \pm 0.2$ & $4.1 \pm 0.2$ & $0.86 \pm 0.5$ & $219.6 \pm 0.7$ & $464 \pm 1.3$ \\
\hline $10 \mu \mathrm{M}$ & $86.1 \pm 0.2$ & $4.4 \pm 0.1$ & $0.86 \pm 0.5$ & $275.4 \pm 0.7$ & $479 \pm 1.4$ \\
\hline $15 \mu \mathrm{M}$ & $87.0 \pm 0.2$ & $4.7 \pm 0.1$ & $0.86 \pm 0.5$ & $333.2 \pm 0.7$ & $487 \pm 1.6$ \\
\hline $20 \mu \mathrm{M}$ & $88.9 \pm 0.2$ & $5.5 \pm 0.1$ & $0.84 \pm 0.5$ & $391.6 \pm 0.7$ & $506 \pm 1.7$ \\
\hline
\end{tabular}


Table S11: The EIS circuit parameters calculated after 3NP binding at the 4NP templated PNIPAM-MAA-VP polymer grafted to the gold electrode.

\begin{tabular}{|c|c|c|c|c|c|}
\hline \multicolumn{6}{|c|}{ Circuit Parameters } \\
\hline \multicolumn{6}{|c|}{$(0.5 \mu \mathrm{g} / \mathrm{ml})$ PNIPAM-MAA-VP (2mins) grafted to the gold electrode for $3 \mathrm{NP}$ binding } \\
\hline \multirow{2}{*}{ Samples } & \multirow{2}{*}{\begin{tabular}{|c|}
$\begin{array}{l}\text { Electrolyte } \\
\text { Resistance }\end{array}$ \\
$R_{s}(\Omega)$ \\
\end{tabular}} & \multicolumn{4}{|c|}{ PNIPAM-MAA-VP Interface } \\
\hline & & $Q_{1}\left(\mu F . s^{n-1}\right)$ & $n$ & $\boldsymbol{R}_{c t}(\boldsymbol{\Omega})$ & $A_{W}\left(\Omega . s^{-0.5}\right)$ \\
\hline $0 \mu \mathrm{M}$ & $86.7 \pm 0.2$ & $4.1 \pm 0.2$ & $0.87 \pm 0.5$ & $165.8 \pm 0.7$ & $489 \pm 1.2$ \\
\hline $1 \mu \mathrm{M}$ & $87.3 \pm 0.2$ & $4.9 \pm 0.3$ & $0.87 \pm 0.5$ & $164.3 \pm 0.8$ & $536 \pm 1.3$ \\
\hline $5 \mu \mathrm{M}$ & $87.0 \pm 0.2$ & $4.9 \pm 0.3$ & $0.87 \pm 0.5$ & $152.8 \pm 0.8$ & $543 \pm 1.3$ \\
\hline $10 \mu \mathrm{M}$ & $87.3 \pm 0.2$ & $5.0 \pm 0.3$ & $0.87 \pm 0.5$ & $154.5 \pm 0.8$ & $537 \pm 1.3$ \\
\hline $15 \mu \mathrm{M}$ & $87.1 \pm 0.2$ & $4.9 \pm 0.3$ & $0.87 \pm 0.5$ & $149.3 \pm 0.8$ & $546 \pm 1.3$ \\
\hline $20 \mu \mathrm{M}$ & $86.9 \pm 0.2$ & $5.0 \pm 0.3$ & $0.87 \pm 0.5$ & $147.3 \pm 0.8$ & $544 \pm 1.2$ \\
\hline
\end{tabular}


Figure S6(a, c) depict no significant Bode magnitude and phase changes in the polymer-modified electrode upon exposure to different concentrations of 3NP. However, when exposed to 4NP, there is a significant change in both magnitude and phase of the Bode plot due to binding of 4NP to the target-templated PNIPAM-MAA-VP copolymer. Such shifting in the Bode plot occurs due to conformational changes in the polymer chains upon binding of $4 \mathrm{NP}$, as shown in Table $\mathbf{S}$. This frequency response may also include some contribution from cluster type or highly crosslinked polymers at the interface. The visible change occurred in charge transfer resistance upon target binding follows random linear coil to folded transition of the polymer chains, thus hindering the diffusion paths for redox mediators at the polymer-gold interface. The absence of a completely flat lower frequency profile at the bode plot indicates that there is the presence of some polymer chains that do not participate in target binding. Such a scenario is related to the absence of functional monomers or template recognition sites.
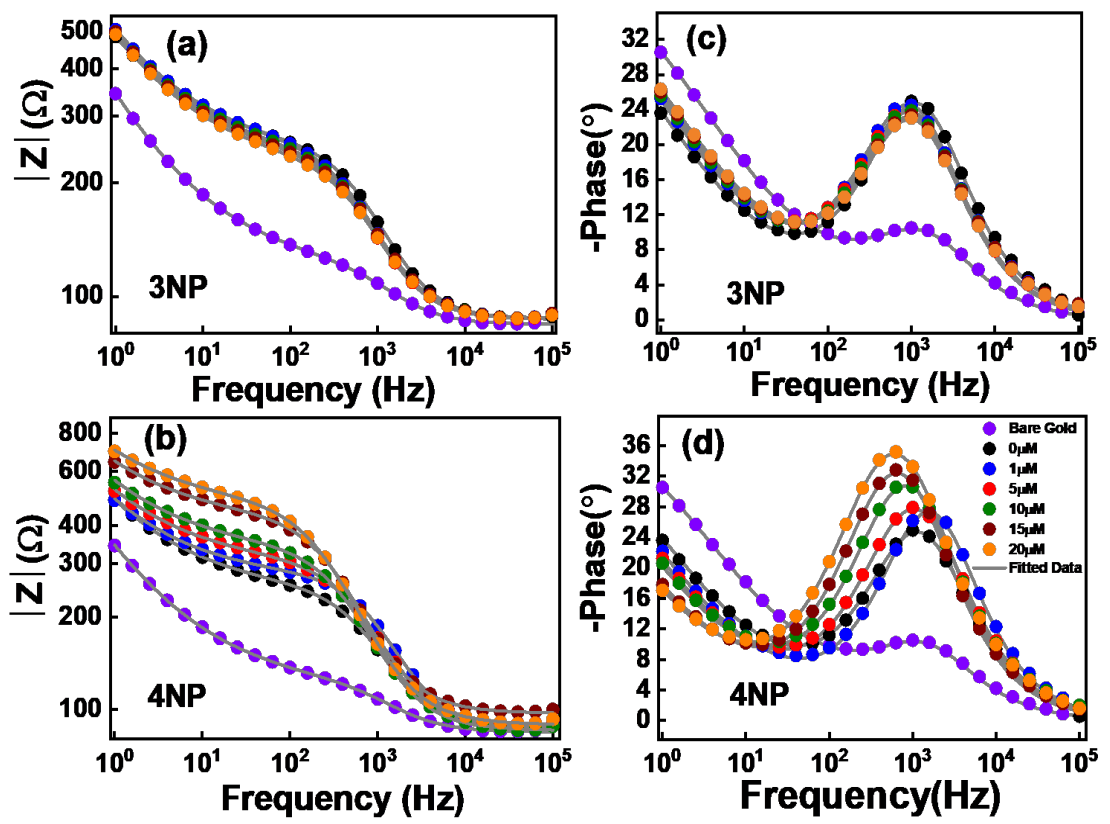

Figure S6: The Bode magnitude $(a, b)$ and phase $(c, d)$ plots for conformational changes of the 4-NP-templated copolymer upon exposure to different concentrations of $3 N P(a, c)$ and $4 N P(b, d)$. The Bode plots estimate the change in impedance and phase upon binding of the target. Upon binding, the polymer undergoes a conformational change from random coil to folded state which essentially changes the lower frequency diffusion impedance and 
Table S12: The binding affinity and apparent rate constant estimation after binding via EIS parameters of $4 N P$-templated copolymers upon binding of $4 N P$ (template), $3 N P$, and $2 N P$. These parameters were fitted in Figure $7(\boldsymbol{c} \& f)$

\section{Binding Parameters}

(0.5 $\mathrm{g} / \mathrm{ml})$ PNIPAM-MAA-VP (2mins) grafted to gold electrode for template binding

\begin{tabular}{|c|c|c|c|c|c|c|}
\hline \multirow{2}{*}{ Concentration } & \multicolumn{2}{|r|}{$3 N P$} & \multicolumn{2}{|r|}{$4 N P$} & \multicolumn{2}{|c|}{$2 N P$} \\
\hline & $* * \frac{\Delta \boldsymbol{R}_{c t}}{\boldsymbol{R}_{c t, 0 \mu M}}$ & $\begin{array}{c}{ }^{*} K_{a p p}\left(\mathrm{~cm} \cdot \mathrm{s}^{-1}\right) \times \\
10^{-3}\end{array}$ & $* * \frac{\Delta \boldsymbol{R}_{c t}}{\boldsymbol{R}_{c t, 0 \mu M}}$ & $\begin{array}{c}{ }^{*} K_{a p p}\left(\mathrm{~cm} \cdot \mathrm{s}^{-1}\right) \times \\
10^{-3}\end{array}$ & $* * \frac{\Delta \boldsymbol{R}_{c t}}{\boldsymbol{R}_{c t, 0 \mu M}}$ & $\begin{array}{c}{ }^{*} K_{a p p}\left(\mathrm{~cm} \cdot \mathrm{s}^{-1}\right) \times \\
10^{-3}\end{array}$ \\
\hline $0 \mu \mathrm{M}$ & 0 & $4.6 \pm 0.02$ & 0 & $4.6 \pm 0.02$ & 0 & $4.6 \pm 0.02$ \\
\hline $1 \mu \mathrm{M}$ & 0 & $4.6 \pm 0.02$ & $0.09 \pm 0.001$ & $4.2 \pm 0.01$ & $0.04 \pm\left(3 \times 10^{-5}\right)$ & $4.4 \pm 0.02$ \\
\hline $5 \mu \mathrm{M}$ & 0 & $4.9 \pm 0.02$ & $0.33 \pm 0.001$ & $3.4 \pm 0.01$ & 0 & $4.7 \pm 0.02$ \\
\hline $10 \mu \mathrm{M}$ & 0 & $4.9 \pm 0.02$ & $0.66 \pm 0.003$ & $2.7 \pm 0.008$ & 0 & $4.8 \pm 0.02$ \\
\hline $15 \mu \mathrm{M}$ & 0 & $5.0 \pm 0.02$ & $1.01 \pm 0.004$ & $2.2 \pm 0.005$ & $0.02 \pm\left(1.1 \times 10^{-4}\right)$ & $4.5 \pm 0.02$ \\
\hline $20 \mu \mathrm{M}$ & 0 & $5.1 \pm 0.02$ & $1.37 \pm 0.006$ & $1.9 \pm 0.003$ & $0.06 \pm\left(1.1 \times 10^{-4}\right)$ & $4.3 \pm 0.02$ \\
\hline \multicolumn{7}{|c|}{${ }^{*} K_{a p p}=\frac{R T}{n F^{2} C A R_{c t}}$} \\
\hline
\end{tabular}


Table S13: The EIS circuit parameters calculated after 2NP binding to the 4NP-templated copolymer grafted to the gold electrode.

\begin{tabular}{|c|c|c|c|c|c|}
\hline \multicolumn{6}{|c|}{ Circuit Parameters } \\
\hline \multicolumn{6}{|c|}{$(0.5 \mu \mathrm{g} / \mathrm{ml})$ PNIPAM-MAA-VP (2mins) grafted to gold electrode for $2 N P$ binding } \\
\hline \multirow{2}{*}{ Samples } & \multirow{2}{*}{$\begin{array}{c}\begin{array}{c}\text { Electrolyte } \\
\text { Resistance }\end{array} \\
R_{s}(\Omega) \\
\end{array}$} & \multicolumn{4}{|c|}{ PNIPAM-MAA-VP Interface } \\
\hline & & $Q_{1}\left(\mu F . s^{n-1}\right)$ & $n$ & $\boldsymbol{R}_{c t}(\boldsymbol{\Omega})$ & $A_{W}\left(\Omega . s^{-0.5}\right)$ \\
\hline $0 \mu \mathrm{M}$ & $86.7 \pm 0.2$ & $4.1 \pm 0.2$ & $0.87 \pm 0.5$ & $165.2 \pm 0.7$ & $489.3 \pm 1.2$ \\
\hline $1 \mu \mathrm{M}$ & $80.9 \pm 0.2$ & $4.9 \pm 0.2$ & $0.87 \pm 0.5$ & $172.1 \pm 0.8$ & $489.6 \pm 1.3$ \\
\hline $5 \mu \mathrm{M}$ & $85.6 \pm 0.2$ & $3.9 \pm 0.2$ & $0.88 \pm 0.5$ & $160.2 \pm 0.7$ & $490 \pm 1.1$ \\
\hline $10 \mu \mathrm{M}$ & $86.8 \pm 0.2$ & $5.8 \pm 0.4$ & $0.83 \pm 0.5$ & $152.8 \pm 0.8$ & $494.7 \pm 1.3$ \\
\hline $15 \mu \mathrm{M}$ & $89.3 \pm 0.2$ & $4.1 \pm 0.2$ & $0.87 \pm 0.5$ & $169.3 \pm 0.7$ & $490 \pm 1.2$ \\
\hline $20 \mu \mathrm{M}$ & $90.4 \pm 0.2$ & $4.7 \pm 0.3$ & $0.86 \pm 0.5$ & $176.1 \pm 0.7$ & $499.3 \pm 1.3$ \\
\hline
\end{tabular}


4-NP, 3-NP, and TCEP Adsorption Effects in the Electrochemical Signal at Bare Gold Surface

Figure S7(c) reflects that the exposing the bare gold electrode to $40 \mu \mathrm{M}$ of 3-NP, 4-NP, and TCEP solution for 5 minutes show no interference by adsorption of such analytes. No visual change in the signal in the liquid electrolyte medium $\left(5 \mathrm{mM} \mathrm{K}_{4 / 3} \mathrm{Fe}(\mathrm{CN})_{6}\right.$ dissolved in $1 \mathrm{X}$ PBS, $\left.\mathrm{pH}: 7.1\right)$ was observed for all the analytes compared to the clean bare gold electrode. Figure S7(d) inset shows oxidation and reduction of $1 \mathrm{mM} 4 \mathrm{NP}$ in $1 \mathrm{X}$ PBS at the gold surface via bulk diffusion in the CV. The redox peaks are different and appear more anodic compared to the liquid electrolyte medium $\left(5 \mathrm{mM} \mathrm{K}_{4 / 3} \mathrm{Fe}(\mathrm{CN})_{6}\right.$ dissolved in $1 \mathrm{X}$ PBS, $\left.\mathrm{pH}: 7.1\right)$.
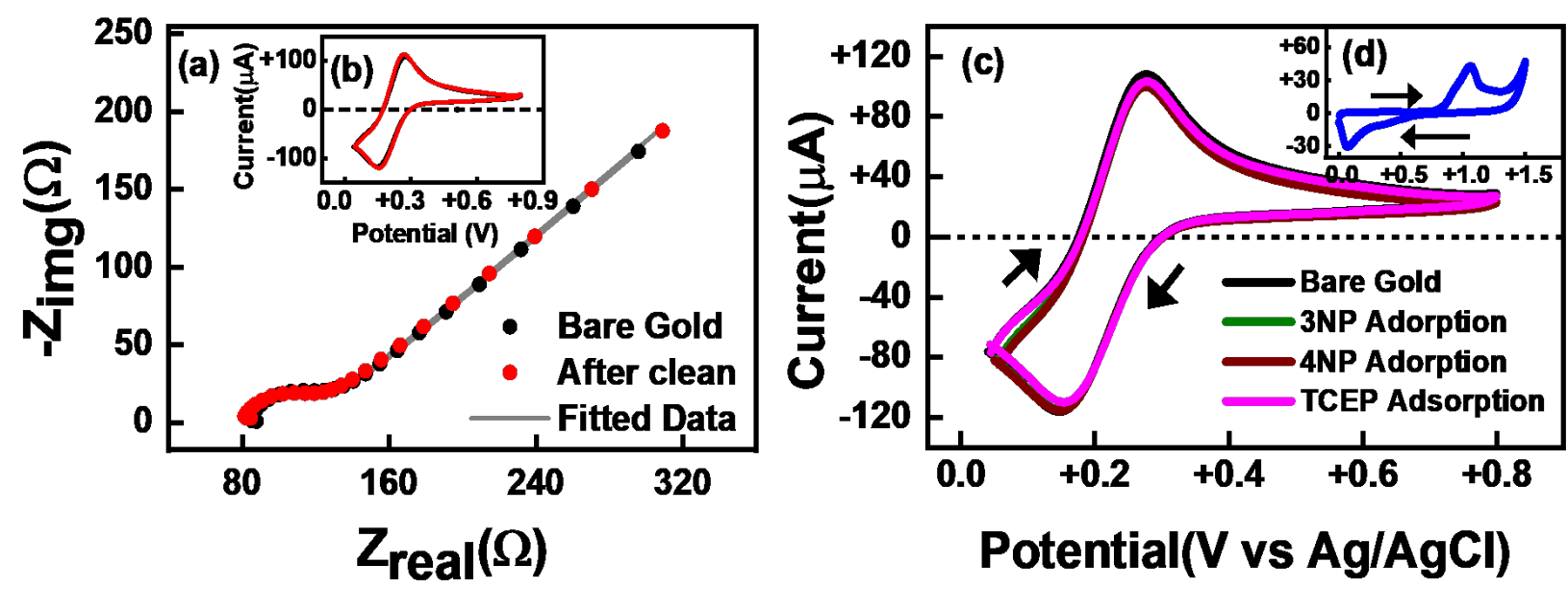

Figure S7: The Nyquist plot (a) and the $C V$ (b) shows similar kinetics and charge transfer recovered after cleaning the polymer-gold surface. The plots indicate that gold electrodes can be reused for the polymer grafting. (c) The CV shows no interference or chemical change happening at the bare gold surface via adsorption of templates (3NP, 4NP) and the reaction of reducing agents (TCEP) after exposure for 5 mins. Such phenomenon signifies the changes observed in the electrochemical characterization in Figure 4 at polymer-gold surface are not triggered via any adsorption or other side chemical reaction at the bare gold surface. (d) Inset $C V$ (blue curve) shows that the diffusion of $4 N P$ from the bulk solution to the gold surface

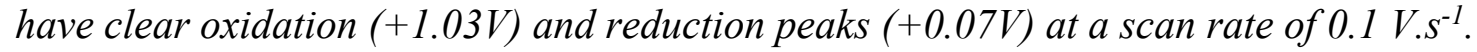



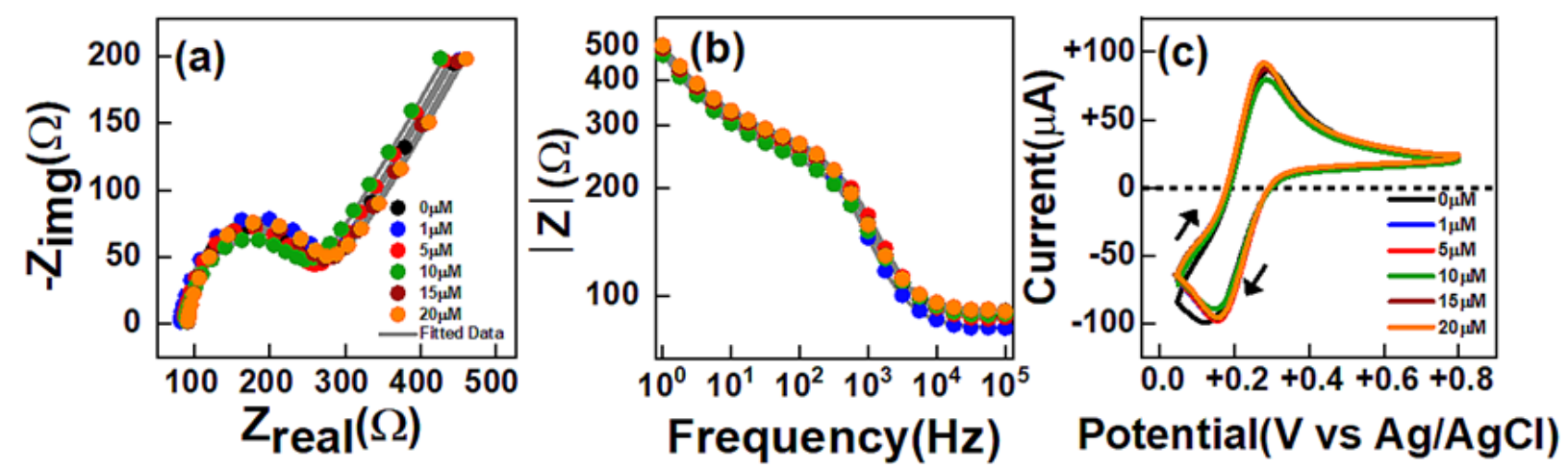

Figure S8: The Nyquist plot (a) for different concentrations of 2NP for PNIPAM-MAA-VP samples. The Bode magnitude plot (b) and CV curve (c) at different $2 \mathrm{NP}$ levels were recorded to estimate the change in overall impedance and charge transfer at the polymer interface, respectively. 


\section{Effective Chemical Cleaning of the PNIPAM-MAA-VP Polymer grafted to the Gold Electrode Before and After the Sensing Experiment}

The PNIPAM-MAA-VP polymer is attached to the gold surface via a thiol bond. Before polymer attachment, gold electrodes are first cleaned in $0.5 \mathrm{M} \mathrm{NaOH}$ by cycling the electrode potential between -0.4 to $-1.6 \mathrm{~V}\left(10\right.$ cycles, scan rate: $\left.0.05 \mathrm{~V}-\mathrm{s}^{-1}\right)$. After initial cyclic cleaning, the gold electrodes are polished on a micro cloth pad in $0.05 \mu \mathrm{m}$ diamond slurries, followed by ultrasonic cleaning in D.I water. After polishing, the gold surfaces are rinsed with profuse D.I water and electrochemically polished in $0.5 \mathrm{M} \mathrm{H}_{2} \mathrm{SO}_{4}$ (from -0.3 to $+0.9 \mathrm{~V}, 10$ cycles, scan rate: $\left.0.3 \mathrm{~V}-\mathrm{s}^{-1}\right)$. After electrochemical polishing, the gold electrodes are sequentially cleaned ultrasonically in D.I water followed by ethanol for $10 \mathrm{~min} .{ }^{44}$ Post sensing and surface coverage experiments, the polymer-modified electrodes were exposed to the overnight (12 h) cleaning of the gold surface in a solution containing D.I water, $\mathrm{NH}_{4} \mathrm{OH}$, and $\mathrm{H}_{2} \mathrm{O}_{2}$ in a specific $(63: 2: 1)$ molar ratio. ${ }^{45}$ Afterward, the overnight cleaning of gold electrodes was performed using a micro cloth polishing with diamond slurry, followed by electrochemical polishing and ultrasonic cleaning in D.I water and ethanol. After a complete washing, the gold electrodes were dried via $\mathrm{N}_{2}$ purging for use again for characterization and further polymer grafting. Figure S7(a, b) show that the CVs and Nyquist plots of the washed bare gold electrode and those of the cleaned gold surface after polymer grafting are identical. 


\section{Grafting of the Polymers to a Gold Electrode}


3 electrode setup for electrochemical characterization

MIP attached Au working electrode

Figure S9: A schematic diagram of attaching the copolymers to the gold electrode and a threeelectrode setup for electrochemical characterization of the polymer-modified electrode. 


\section{Real Water Sample Preparation and Sensing of 4-NP via Templated Polymer-Modified Gold Electrode:}

The river water sample (collected from Salmon falls river near Dover, NH, USA) was filtered to remove insoluble solid impurities. To test the sensor's selectivity against interfering species, three organic compounds, Phenol, 2-Chlorophenol, and 2-Aminophenol were chosen and added to the sample water $(20 \mu \mathrm{M}$ each). These chemicals were chosen as possible interferents due to their similarity in chemical structure to 4-NP. A filter paper of $10 \mu \mathrm{m}$ pore size was used for filtration, and the $\mathrm{pH}$ was adjusted to 7 for both tap and river water samples. Figure S10 shows the images of the location where the sample was collected as well as the sample preparation steps. Our electrochemical sensing results revealed that both samples contained no measurable traces of 4NP. Afterward, an aliquot of 4-NP $(0-20 \mu \mathrm{M})$ was added to the river and tap water samples which already contained the three interfering species $(20 \mu \mathrm{M}$ each). The prepared water samples $(20 \mathrm{~mL}$ in volume) were exposed to the polymer-modified gold electrode sensor for 1 minute before running the electrochemical measurements. Figure S11 shows the sensing results in tap water with and without interfering species added.

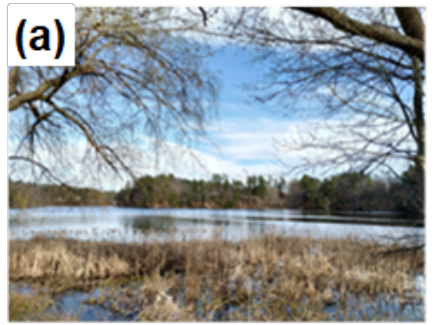

Salmon Falls River

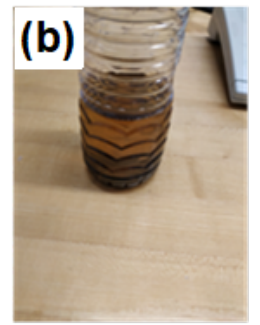

Unflitered



Flitered
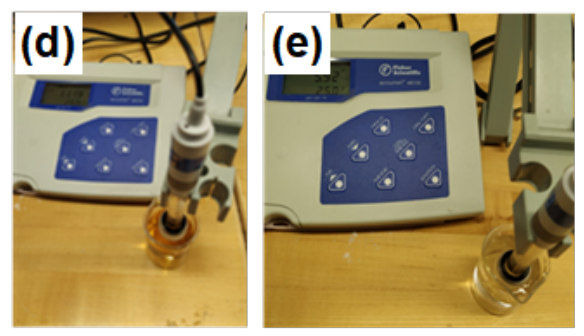

pH adjustments of samples

Figure S10: Preparation of the river water samples for 4-NP measurement. The images show (a) the river water sample collected from Salmon Falls River, Dover, NH, USA; (b) the unfiltered river water and (c) the sample after filtering with a filter paper. (d) The filtered river water initially had a $\mathrm{pH}$ of 11.19 and was adjusted to 7 by adding $1 \mathrm{M} \mathrm{HCl}$. (e) The as-received tap water had a pH of 5.92 and was adjusted to 7 by adding $0.5 \mathrm{M} \mathrm{NaOH}$. 


\section{NP detection in regular tap water}
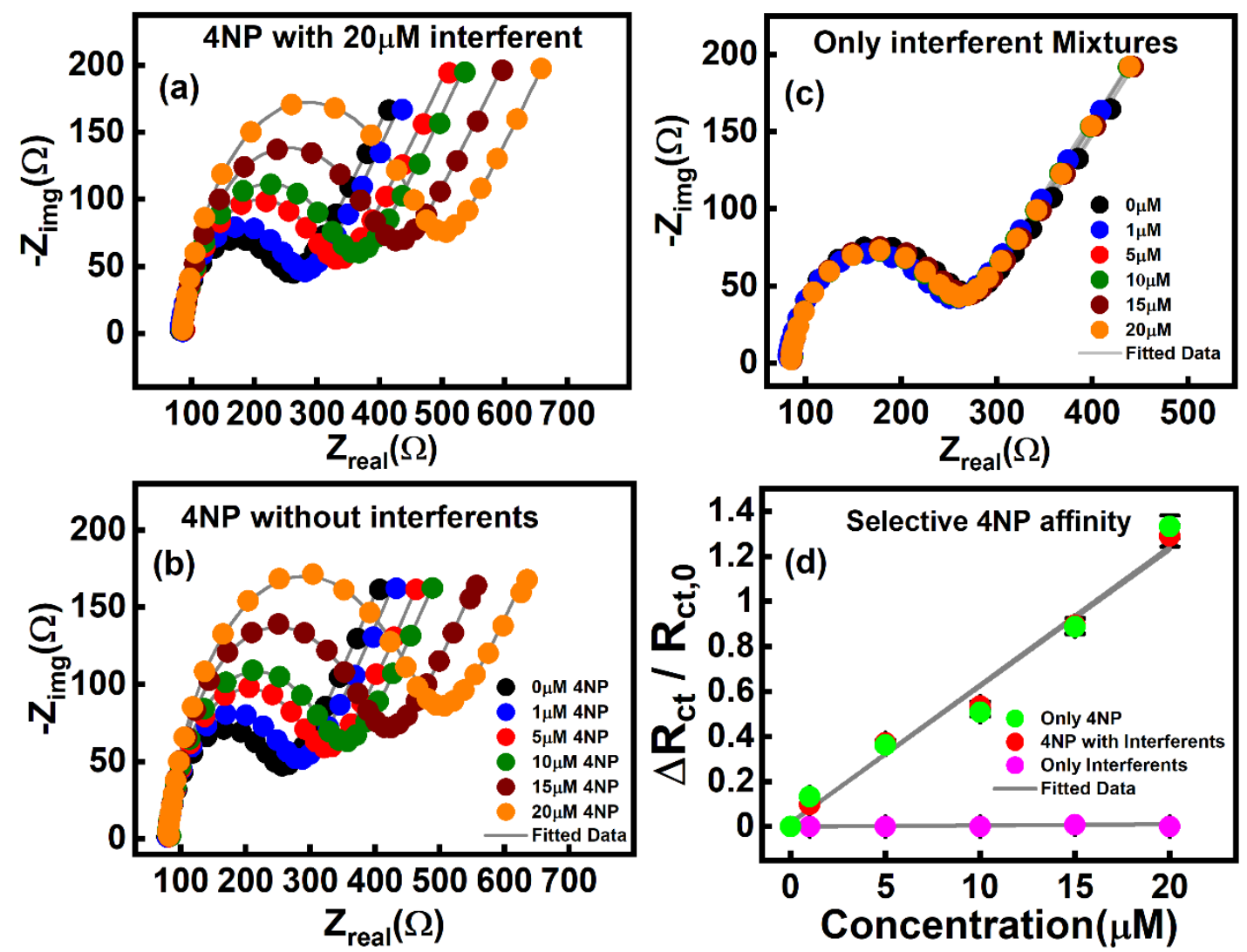

Figure S11: Selective binding of 4-NP was assessed via electrochemical sensing on tap water. (a) After exposing the sensor to varying concentrations of 4-NP in the presence of a $20 \mu \mathrm{M}$ mixture of interferents; (b) After exposing the sensor to varying concentrations of 4-NP without any interferents added; (c) After exposing the sensor to varying concentrations of interferents; (d) The calibration curve for $\left(\Delta R_{c t} / R_{c t, 0}\right)$ versus $4-N P$ concentrations. Legends for $(a-c)$ : $0 \mu M(b l a c k)$; $1 \mu M$ (blue); $5 \mu M$ (red); $10 \mu M$ (green); $15 \mu M$ (brown); $20 \mu M$ (orange). Legends for (d): 4-NP only (green), 4-NP with interferents (red), and interferents only (magenta). 


\section{Reproducibility and Stability Test of the 4-NP Sensor}

To further characterize the reproducibility, the developed sensor was tested on three different days (day 1, day 4, and day 7). The results in Figure S12 shows that over the 7-day period, the measurements were consistent with minor variations among days 1, 4, and 7.
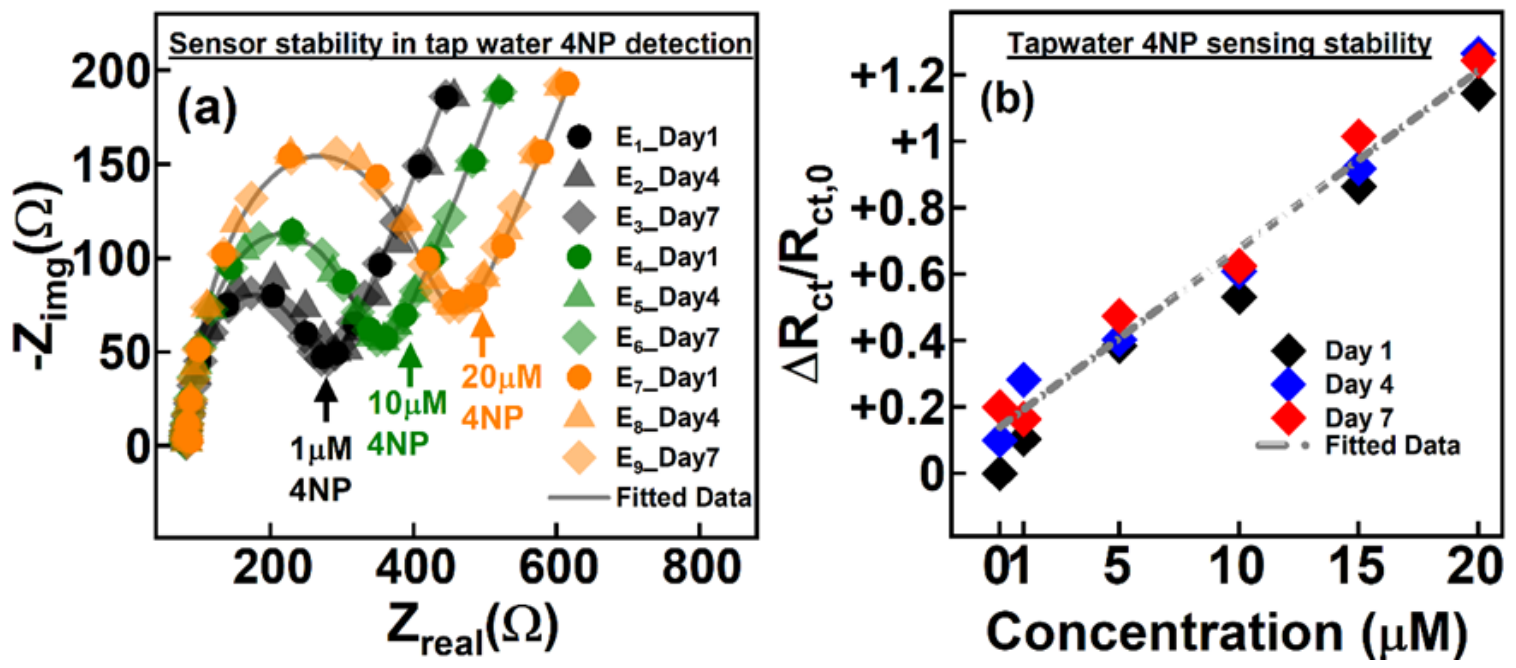

Figure S12: The study of reproducibility and stability of the templated polymer-based 4-NP sensor in tap water (without any interferents added) at room temperature. Nine individual polymerattached gold electrodes $\left(E_{1}-E_{9}\right)$ were prepared under the same grafting conditions. The electrodes $E_{1}, E_{4}$, and $E_{7}$ were used on Day 1, electrodes $E_{2}, E_{5}$, and $E_{8}$ were used on Day 4 , and electrodes $E_{3}, E_{6}$, and $E_{9}$ were used on Day 7. (a) The Nyquist plots showing the sensor responses over 7 days with three different 4-NP concentrations tested during this period. Legends: $1 \mu M$ (black), $10 \mu M$ (green), and $20 \mu M$ (orange); (b) The calibration curve $\left(\Delta R_{c t} / R_{c t, 0} v s\right.$. 4-NP concentration) demonstrates reasonable stability over the 7-day period.

The $\mathrm{R}_{\mathrm{ct}}$ obtained via circuit fitting in Figure $\mathbf{S 1 2}$ shows no concurrent change in the same 4-NP concentration signals for the $1^{\text {st }}, 4^{\text {th }}$, and $7^{\text {th }}$ day in tap water. The charge transfer resistance change $\left(\Delta \mathrm{R}_{\mathrm{ct}} / \mathrm{R}_{\mathrm{ct}, 0}\right)$ obtained for a range of $4-\mathrm{NP}$ concentration (0 to $\left.20 \mu \mathrm{M}\right)$ for 3 different days results in three different slopes (SD: \pm 0.0028 ) with an average of 0.05436 . The relative standard deviation (RSD) of 5.305\% (\% value of SD w.r.t average) indicates a stable and reproducible sensing results in terms of charge transfer resistance change in the laboratory tap water. The LOD (limit of detection) and LOQ (Limit of quantification) were calculated from the linear fitting in Figure S13 $\left(R^{2} \sim 0.98552\right)$ in tap water and river water via the following equations:

$L O D=\frac{3 \sigma}{m}$

Eq. S1 
$\mathrm{LOQ}=\frac{10 \sigma}{\mathrm{m}}$

The $\sigma$ represents the SD of the $\mathrm{R}_{\mathrm{ct}}$ in the blank solution $(0 \mu \mathrm{M})$ and the $\mathrm{m}$ is the slope of the linear range obtained from Figure S13. The LOD and LOQ obtained for 4NP in tap water were (1.95 \pm $0.046) \mu \mathrm{M}$ and $(6.53 \pm 0.15) \mu \mathrm{M}$, respectively. Similarly, the LOD of $\sim 1 \mu \mathrm{M}$ and LOQ of $\sim 3.2 \mu \mathrm{M}$ were obtained for 4-NP detection in river water samples.



Figure S13: The $\Delta R_{c t}$ calibration obtained for binding of various concentrations of 4-NP in tap water (red) and in the river water sample (green). The $\Delta R_{c t}$ calibration was performed at room temperature. The $L O D$ and $L O Q$ obtained were $(1.95 \pm 0.046) \mu M$ and $(6.53 \pm 0.15) \mu M$, respectively in tap water. The slope obtained via linear fitting have correlation factors $R^{2}=$ 0.98552 (tap water) and $R^{2}=0.98326$ (river water). The standard deviation (SD) of $R_{c t}$ of $0 \mu M$ of $4 N P$ in tap water and river samples are 6.17 and 3.92, respectively. 


\section{TEM Imaging of the Synthesized Polymers on Gold Surfaces}

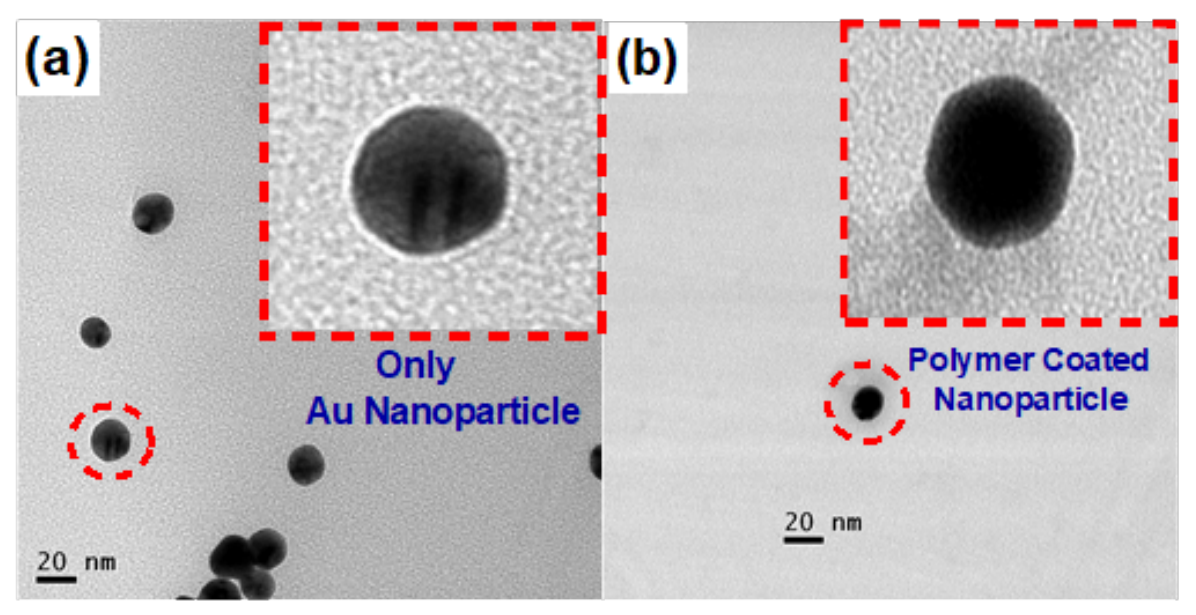

Figure S14: TEM images of gold (Au) nanoparticles (diameter of $20 \mathrm{~nm}$ ). (a) Au nanoparticles dispersed in 0.1mM PBS drop casted on lacey carbon grids; (b) A Au nanoparticle coated with 100-mer PNIPAM-MAA-VP copolymers in the presence of TCEP. The solution containing $1 \mathrm{mg} / \mathrm{L}$ copolymer and $0.01 \mathrm{mg} / \mathrm{L}$ TCEP in $5 \mathrm{~mL}$ of DI water was added into a dispersed gold nanoparticle solution. The final solution was kept lightly stirred for 2 mins and then drop casted on carbon grids with a $5 \mu \mathrm{L}$ droplet. Both insets are magnified images of the particular nanoparticles circled in red. The inset in (b) shows polymer grafted to the Au nanoparticles (a light grey area near Au nanoparticle). 


\section{Comparison Between Templated and Non-Templated Polymers}

We have synthesized the non-templated polymer under the identical condition but in the absence of the template (4-NP). As shown in Figure S15, we have compared the FTIR spectra between the templated (red) and non-templated (black) polymers and have found no major distinguishable differences. This suggests that the molecular composition (in terms of the mol \% of NIPAM, MAA, and VP) is similar between the two types of polymers. To further distinguish between the templated and non-templated polymers, we have performed the electrochemical sensing of 4-NP as shown in Figure S16 and found that the electrode modified with the non-templated polymer did not exhibit a concentration-dependent response when exposed to 4-NP molecules.

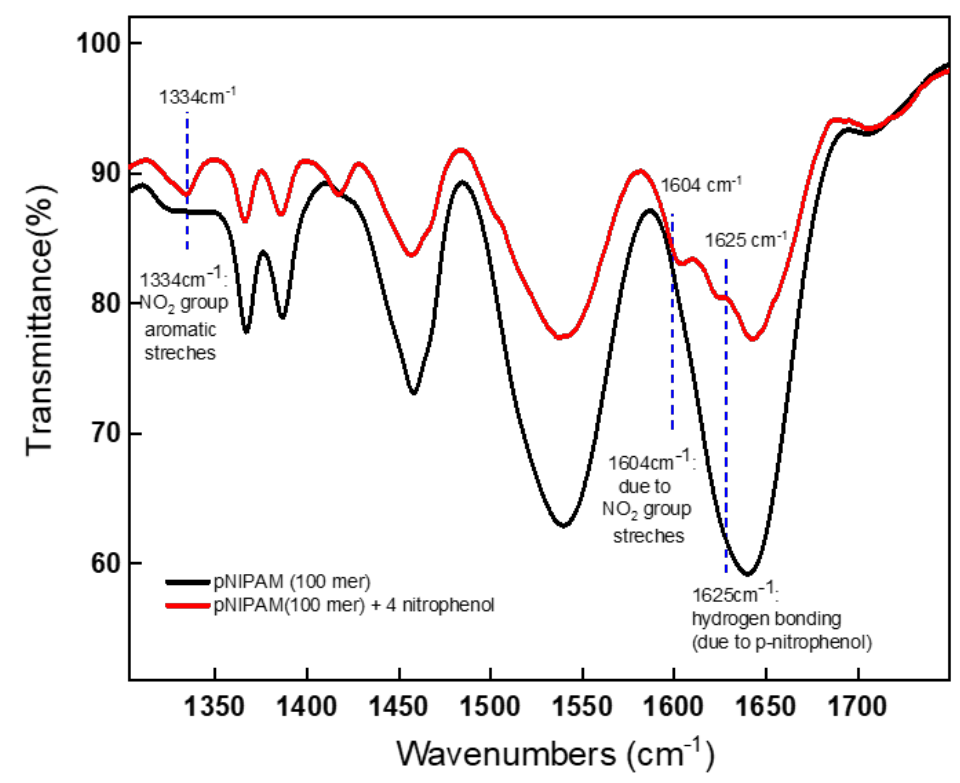

Figure S15: FTIR spectra of templated (red) and non-templated (black) copolymers. 



Figure S16: (a) Nyquist plot of non-templated PNIPAM-MAA-VP copolymer upon exposure to varying concentrations of 4-NP. (b) Plots of the apparent rate constant $\left(K_{\text {app }}\right)$ and the charge transfer resistance change $\left(\Delta R_{c t} / R_{c t, 0}\right)$ for the non-templated polymer versus target (4-NP) concentration. No clear concentration-dependent change was observed in both plots. 


\section{REFERENCES:}

(1) Futscher, M. H.; Philipp, M.; Müller-Buschbaum, P.; Schulte, A. The Role of Backbone Hydration of Poly(N-Isopropyl Acrylamide) Across the Volume Phase Transition Compared to Its Monomer. Sci. Rep. 2017, 7 (1), 1-10. https://doi.org/10.1038/s41598-01717272-7.

(2) Krimm, S.; Bandekar, J. Vibrational Spectroscopy and Conformation of Peptides, Polypeptides, and Proteins. In Advances in Protein Chemistry; Anfinsen, C. B., Edsall, J. T., Richards, F. M., Eds.; Academic Press, 1986; Vol. 38, pp 181-364. https://doi.org/10.1016/S0065-3233(08)60528-8.

(3) Ajmal, M.; Farooqi, Z. H.; Siddiq, M. Silver Nanoparticles Containing Hybrid Polymer Microgels with Tunable Surface Plasmon Resonance and Catalytic Activity. Korean J. Chem. Eng. 2013, 30 (11), 2030-2036. https://doi.org/10.1007/s11814-013-0150-4.

(4) Xu, W.; Yin, X.; He, G.; Zhao, J.; Wang, H. Photografted Temperature-Sensitive Poly(NIsopropylacrylamide) Thin Film with a Superfast Response Rate and an Interesting Transparent-Opaque-Transparent Change in Its Deswelling Process. Soft Matter 2012, 8 (11), 3105-3111. https://doi.org/10.1039/C2SM07404D.

(5) Rao, C. N. R.; Venkataraghavan, R.; Kasturi, T. R. Contribution to the Infrared Spectra of Organosulphur Compounds. Can. J. Chem. 1964, 42 (1), 36-42. https://doi.org/10.1139/v64-006.

(6) Fadida, T.; Lellouche, J.-P. Preparation and Characterization of Composites Built of Poly(N-Benzophenoyl Methacrylamide-Co-N-Hydroxyethyl Acrylamide) Cores and Silica Raspberry-like Shells with Dual Orthogonal Functionality. J. Colloid Interface Sci. 2012, 386 (1), 167-173. https://doi.org/10.1016/j.jcis.2012.07.023.

(7) Bucatariu, S.; Fundueanu, G.; Prisacaru, I.; Balan, M.; Stoica, I.; Harabagiu, V.; Constantin, M. Synthesis and Characterization of Thermosensitive Poly(N-Isopropylacrylamide-CoHydroxyethylacrylamide) Microgels as Potential Carriers for Drug Delivery. J. Polym. Res. 2014, 21 (11), 580. https://doi.org/10.1007/s10965-014-0580-7.

(8) Patterson, J. P.; Kelley, E. G.; Murphy, R. P.; Moughton, A. O.; Robin, M. P.; Lu, A.; Colombani, O.; Chassenieux, C.; Cheung, D.; Sullivan, M. O.; Epps, T. H.; O’Reilly, R. K. Structural Characterization of Amphiphilic Homopolymer Micelles Using Light Scattering, SANS, and Cryo-TEM. Macromolecules 2013, 46 (15), 6319-6325. https://doi.org/10.1021/ma4007544.

(9) Xiao, Z.-P.; Yang, K.-M.; Liang, H.; Lu, J. Synthesis of Magnetic, Reactive, and Thermoresponsive Fe3O4 Nanoparticles via Surface-Initiated RAFT Copolymerization of N-Isopropylacrylamide and Acrolein. J. Polym. Sci. Part Polym. Chem. 2010, 48 (3), 542550. https://doi.org/10.1002/pola.23752. 
(10) Oyeneye, O. O.; Xu, W. Z.; Charpentier, P. A. Adhesive RAFT Agents for Controlled Polymerization of Acrylamide: Effect of Catechol-End R Groups. $R S C A d v$. 2015, 5 (94), 76919-76926. https://doi.org/10.1039/C5RA16193B.

(11) Zander, N. E.; Orlicki, J. A.; Rawlett, A. M. Thermal and FTIR Characterization of Poly (4-Vinylpyridine) Crosslinked with Metal Salts; ARL-TR-5108; US Army Research Laboratory, 2010.

(12) Yanti; Nurhayati, T.; Royani, I.; Widayani; Khairurrijal. Synthesis and Characterization of MAA-Based Molecularly-Imprinted Polymer (MIP) with D-Glucose Template. J. Phys. Conf. Ser. 2016, 739, 012143. https://doi.org/10.1088/1742-6596/739/1/012143.

(13) Preparation and characterization of dendrimer-star PNIPAAM using dithiobenzoateterminated PPI dendrimer via RAFT polymerization - ScienceDirect https://www.sciencedirect.com/science/article/pii/S0014305705003952?via\%3Dihub (accessed Nov 1, 2019).

(14) Tarabukina, E.; Rozanova, A.; Filippov, A.; Constantin, M.; Harabagiu, V.; Fundueanu, G. Thermo- and PH-Responsive Phase Separation of N-Isopropylacrylamide with 4Vinylpyridine Random Copolymer in Aqueous Solutions. Colloid Polym. Sci. 2018, 296 (3), 557-565. https://doi.org/10.1007/s00396-018-4269-z.

(15) Methacrylic acid(79-41-4) 1H NMR https:/www.chemicalbook.com/SpectrumEN_79-414_1HNMR.htm (accessed Oct 29, 2019).

(16) Raina, J.-B.; Tapiolas, D.; Willis, B. L.; Bourne, D. G. Coral-Associated Bacteria and Their Role in the Biogeochemical Cycling of Sulfur. Appl. Environ. Microbiol. 2009, 75 (11), 3492-3501. https://doi.org/10.1128/AEM.02567-08.

(17) Nguyen, T. H.; Tran, P. H.; Thai, L. D.; Truong, T. T.; Nguyen, L.-T. T.; Nguyen, H. T. Synthesis and Characterization of the Photoswitchable Poly(Methyl MethacrylateRandom-Methacrylate Spirooxazine). Polímeros 2019, $29 \quad$ (1). https://doi.org/10.1590/0104-1428.01118.

(18) Pérez-Fonseca, A. A.; Gómez, C.; Dávila, H.; González-Núñez, R.; Robledo-Ortíz, J. R.; Vázquez-Lepe, M. O.; Herrera-Gómez, A. Chitosan Supported onto Agave FiberPostconsumer HDPE Composites for Cr(VI) Adsorption. Ind. Eng. Chem. Res. 2012, 51 (17), 5939-5946. https://doi.org/10.1021/ie201242x.

(19) Nishimura, O.; Yabe, K.; Iwaki, M. X-Ray Photoelectron Spectroscopy Studies of HighDose Nitrogen Ion Implanted-Chromium: A Possibility of a Standard Material for Chemical State Analysis. J. Electron Spectrosc. Relat. Phenom. 1989, 49 (3), 335-342. https://doi.org/10.1016/0368-2048(89)85021-2.

(20) Pérez-Fonseca, A. A.; Gómez, C.; Dávila, H.; González-Núñez, R.; Robledo-Ortíz, J. R.; Vázquez-Lepe, M. O.; Herrera-Gómez, A. Chitosan Supported onto Agave FiberPostconsumer HDPE Composites for Cr(VI) Adsorption. Ind. Eng. Chem. Res. 2012, 51 (17), 5939-5946. https://doi.org/10.1021/ie201242x. 
(21) Kudo, Y.; Yoshida, N.; Fujimoto, M.; Tanaka, K.; Toyoshima, I. Acid-Dissociation Behavior of Para-Hydroxyl Group in the N,N,O-Terdentate Ligand, 4-(4-Methyl-2Pyridylazo)Resorcinol, Coordinated to a Transition Metal Ion. Bull. Chem. Soc. Jpn. 1986, 59 (5), 1481-1486. https://doi.org/10.1246/bcsj.59.1481.

(22) Krishnamurthy, S.; Montalti, M.; Wardle, M. G.; Shaw, M. J.; Briddon, P. R.; Svensson, K.; Hunt, M. R. C.; Šiller, L. Nitrogen Ion Irradiation of \$ $\backslash$ mathrm $\{\mathrm{Au}\}(110) \$$ : Photoemission Spectroscopy and Possible Crystal Structures of Gold Nitride. Phys. Rev. B 2004, 70 (4), 045414. https://doi.org/10.1103/PhysRevB.70.045414.

(23) Zhai, G. PH- and Temperature-Sensitive Microfiltration Membranes from Blends of Poly(Vinylidene Fluoride)-Graft-Poly(4-Vinylpyridine) and Poly(N-Isopropylacrylamide). J. Appl. Polym. Sci. 2006, 100 (5), 4089-4097. https://doi.org/10.1002/app.23286.

(24) Inkpen, M. S.; Liu, Z.; Li, H.; Campos, L. M.; Neaton, J. B.; Venkataraman, L. NonChemisorbed Gold-Sulfur Binding Prevails in Self-Assembled Monolayers. Nat. Chem. 2019, 11 (4), 351-358. https://doi.org/10.1038/s41557-019-0216-y.

(25) Castner, D. G.; Hinds, K.; Grainger, D. W. X-Ray Photoelectron Spectroscopy Sulfur 2p Study of Organic Thiol and Disulfide Binding Interactions with Gold Surfaces. Langmuir 1996, 12 (21), 5083-5086. https://doi.org/10.1021/la960465w.

(26) Zhong, C.-J.; Brush, R. C.; Anderegg, J.; Porter, M. D. Organosulfur Monolayers at Gold Surfaces: Reexamination of the Case for Sulfide Adsorption and Implications to the Formation of Monolayers from Thiols and Disulfides. 8.

(27) Spampinato, V.; Parracino, M. A.; La Spina, R.; Rossi, F.; Ceccone, G. Surface Analysis of Gold Nanoparticles Functionalized with Thiol-Modified Glucose SAMs for Biosensor Applications. Front. Chem. 2016, 4. https://doi.org/10.3389/fchem.2016.00008.

(28) Willcock, H.; O’Reilly, R. K. End Group Removal and Modification of RAFT Polymers. Polym. Chem. 2010, 1 (2), 149-157. https://doi.org/10.1039/B9PY00340A.

(29) Pantaine, L.; Humblot, V.; Coeffard, V.; Vallée, A. Sulfamide Chemistry Applied to the Functionalization of Self-Assembled Monolayers on Gold Surfaces. Beilstein J. Org. Chem. 2017, 13 (1), 648-658. https://doi.org/10.3762/bjoc.13.64.

(30) Grabar, K. C.; Allison, K. J.; Baker, B. E.; Bright, R. M.; Brown, K. R.; Freeman, R. G.; Fox, A. P.; Keating, C. D.; Musick, M. D.; Natan, M. J. Two-Dimensional Arrays of Colloidal Gold Particles: A Flexible Approach to Macroscopic Metal Surfaces. Langmuir 1996, 12 (10), 2353-2361. https://doi.org/10.1021/la950561h.

(31) Wagner, A. J.; Wolfe, G. M.; Fairbrother, D. H. Reactivity of Vapor-Deposited Metal Atoms with Nitrogen-Containing Polymers and Organic Surfaces Studied by in Situ XPS. Appl. Surf. Sci. 2003, 219 (3), 317-328. https://doi.org/10.1016/S0169-4332(03)00705-0.

(32) Zuyderhoff, E. M.; Dekeyser, C. M.; Rouxhet, P. G.; Dupont-Gillain, C. C. An AFM, XPS and Wettability Study of the Surface Heterogeneity of PS/PMMA-r-PMAA Demixed Thin 
Films. J. Colloid Interface Sci. $\quad \mathbf{2 0 0 8 ,} \quad 319 \quad$ (1), $\quad$ 63-71. https://doi.org/10.1016/j.jcis.2007.11.007.

(33) Greczynski, G.; Hultman, L. C 1s Peak of Adventitious Carbon Aligns to the Vacuum Level: Dire Consequences for Material's Bonding Assignment by Photoelectron Spectroscopy. ChemPhysChem 2017, 18 (12), 1507-1512. https://doi.org/10.1002/cphc.201700126.

(34) Cho, E. C.; Lee, J.; Cho, K. Role of Bound Water and Hydrophobic Interaction in Phase Transition of Poly(N-Isopropylacrylamide) Aqueous Solution. Macromolecules 2003, 36 (26), 9929-9934. https://doi.org/10.1021/ma034851d.

(35) Zhang, Y.; Furyk, S.; Sagle, L. B.; Cho, Y.; Bergbreiter, D. E.; Cremer, P. S. Effects of Hofmeister Anions on the LCST of PNIPAM as a Function of Molecular Weight. J. Phys. Chem. C 2007, 111 (25), 8916-8924. https://doi.org/10.1021/jp0690603.

(36) Rembert, K. B.; Okur, H. I.; Hilty, C.; Cremer, P. S. An NH Moiety Is Not Required for Anion Binding to Amides in Aqueous Solution. Langmuir 2015, 31 (11), 3459-3464. https://doi.org/10.1021/acs.langmuir.5b00127.

(37) Sharon, D.; Bennington, P.; Liu, C.; Kambe, Y.; Dong, B. X.; Burnett, V. F.; Dolejsi, M.; Grocke, G.; Patel, S. N.; Nealey, P. F. Interrogation of Electrochemical Properties of Polymer Electrolyte Thin Films with Interdigitated Electrodes. J. Electrochem. Soc. 2018, 165 (16), H1028-H1039. https://doi.org/10.1149/2.0291816jes.

(38) Ganesh, V.; Pal, S. K.; Kumar, S.; Lakshminarayanan, V. Self-Assembled Monolayers (SAMs) of Alkoxycyanobiphenyl Thiols on Gold-A Study of Electron Transfer Reaction Using Cyclic Voltammetry and Electrochemical Impedance Spectroscopy. J. Colloid Interface Sci. 2006, 296 (1), 195-203. https://doi.org/10.1016/j.jcis.2005.08.051.

(39) Tsai, C.-Y.; Lin, J.-W.; Huang, Y.-P.; Huang, Y.-C. Effects of the Offset Term in Experimental Simulation on Afterglow Decay Curve. ScientificWorldJournal 2014, 2014, 497270. https://doi.org/10.1155/2014/497270.

(40) Lang, X.; Lenart, W. R.; Sun, J. E. P.; Hammouda, B.; Hore, M. J. A. Interaction and Conformation of Aqueous Poly(N-Isopropylacrylamide) (PNIPAM) Star Polymers below the LCST. Macromolecules 2017, $50 \quad$ (5), 2145-2154. https://doi.org/10.1021/acs.macromol.7b00068.

(41) Nguyen, T. Q.; Breitkopf, C. Determination of Diffusion Coefficients Using Impedance Spectroscopy Data. J. Electrochem. Soc. 2018, 165 (14), E826-E831. https://doi.org/10.1149/2.1151814jes.

(42) Fernández-Sánchez, C.; McNeil, C. J.; Rawson, K. Electrochemical Impedance Spectroscopy Studies of Polymer Degradation: Application to Biosensor Development. TrAC Trends Anal. Chem. 2005, 24 (1), 37-48. https://doi.org/10.1016/j.trac.2004.08.010.

(43) Pauliukaite, R.; Ghica, M. E.; Fatibello-Filho, O.; Brett, C. M. A. Electrochemical Impedance Studies of Chitosan-Modified Electrodes for Application in Electrochemical 
Sensors and Biosensors. Electrochimica Acta 2010, 55 (21), 6239-6247. https://doi.org/10.1016/j.electacta.2009.09.055.

(44) Fischer, L. M.; Tenje, M.; Heiskanen, A. R.; Masuda, N.; Castillo, J.; Bentien, A.; Émneus, J.; Jakobsen, M. H.; Boisen, A. Gold Cleaning Methods for Electrochemical Detection Applications. Microelectron. Eng. 2009, $86 \quad$ (4), 1282-1285. https://doi.org/10.1016/j.mee.2008.11.045.

(45) Kim, D. J.; Pitchimani, R.; Snow, D. E.; Hope-Weeks, L. J. A Simple Method for the Removal of Thiols on Gold Surfaces Using an NH4OH-H2O2-H2O Solution. Scanning 2008, 30 (2), 118-122. https://doi.org/10.1002/sca.20089. 